\title{
Evolution of Pediatric Cardiology over the Last 50 Years - Part IV
}

\section{P Syamasundar Rao, MD*}

\section{Professor of Pediatrics and Medicine, Emeritus Chief of Pediatric Cardiology, Children's} Memorial Hermann Hospital, University of Texas-Houston McGovern Medical School, USA

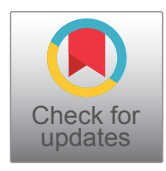

*Corresponding author: P Syamasundar Rao, MD, Professor and Emeritus Chief of Pediatric Cardiology, Children's Memorial Hermann Hospital, University of Texas-Houston McGovern Medical School, 6410 Fannin, UTPB Suite \# 425, Houston, Texas, 77030, USA, Tel: 713-500-5738, Fax: 713-500-5171

\section{Introduction}

The author has just written a book on the evolution of the specialty of Pediatric Cardiology over the last 50 years [1]. The intent of this review is to presenta summary of this book. Because of large amount of the material, the review is separated into four parts. In the Parts I and II, percutaneous interventional procedures were discussed. The Part III reviewed electrocardiography, echocardiography, and cardiac catheterization. In this last paper, subjects that were not discussed in the first three reviews will be presented.

\section{Physiologically Advantageous Ventricular Septal Defects}

In patients with complex heart defects, ventricular septal defect (VSD) is important in maintaining appropriate intra-cardiac shunt; we have recommended that such VSDs are named physiologically advantageous VSD [2]. Spontaneous closure of isolated VSDs was well documented in the 1960s and 1970s [3-8]; yet, closure of physiologically advantageous VSDs was not adequately documented in prior studies [2]. The author initially witnessed spontaneous closure of physiologically advantageous VSDs in two children, one with tricuspid atresia and the other with double outlet right ventricle [2]. This enticed the author to examine this phenomenon further. This issue was thoroughly examined in patients with tricuspid atresia in several studies [9-14]; these studies resulted in documenting functional [9] and anatomical (partial and complete) [2,10-14] closure of VSDs (Figure 1 and Figure 2). These result suggested that spontaneous closure of physiologically advantageous VSDs occurs as often as in isolated VSDs. The mechanisms of closure is also similar to that seen in isolated VSDs. VSD closures were documented to take place in utero, during infancy, childhood, and adolescence and continue through adulthood. It was concluded that there is a great natural tendency for spontaneous closure of VSDs whether it be an isolated defect or is a component of a complex heart defect [10-16].

Spontaneous closure of VSD in children with tricuspid atresia and normally related great arteries (Type I) produces decreased pulmonary blood flow and requires surgical intervention earlier than otherwise needed. We recommended that a Blalock-Taussig (BT) shunt (preferably on the left side) is carried out instead of a Glenn anastomosis (the concept of bidirectional Glenn has not yet been crystallized as of that time) because VSD closure following Glenn will result in no blood flow into the left pulmonary artery (Figure 3). If further palliation is required prior to Fontan procedure, a BT shunt on the right side, Glenn anastomosis, or enlargement of the VSD may be entertained. In subjects with tricuspid atresia and transposition of the great arteries (Type II), VSD closure produces left ventricular outflow obstruction. Therefore, it is highly important that the size of the VSD is appraised before planning for Fontan. If the VSD is small, enlarging the VSD surgically or bypassing the VSD and the right ventricle via a pulmonary artery-to-ascending aorta anastomosis (Damus-Kaye-Stansel) or by a left ventricle-descending aorta conduit (Figure 4) should be considered [10-14]. In addition to tricuspid atresia and double outlet right

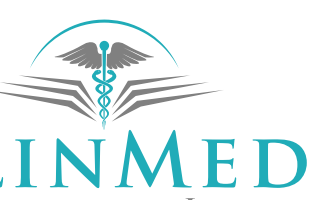

INTERNATIONAL LIBRARY

Citation: Rao PS (2021) Evolution of Pediatric Cardiology over the Last 50 Years - Part IV. Int J Clin Cardiol 8:245. doi.org/10.23937/2378-2951/1410245

Accepted: December 15, 2021: Published: December 17, 2021

Copyright: (c) 2021 Rao PS. This is an open-access article distributed under the terms of the Creative Commons Attribution License, which permits unrestricted use, distribution, and reproduction in any medium, provided the original author and source are credited. 


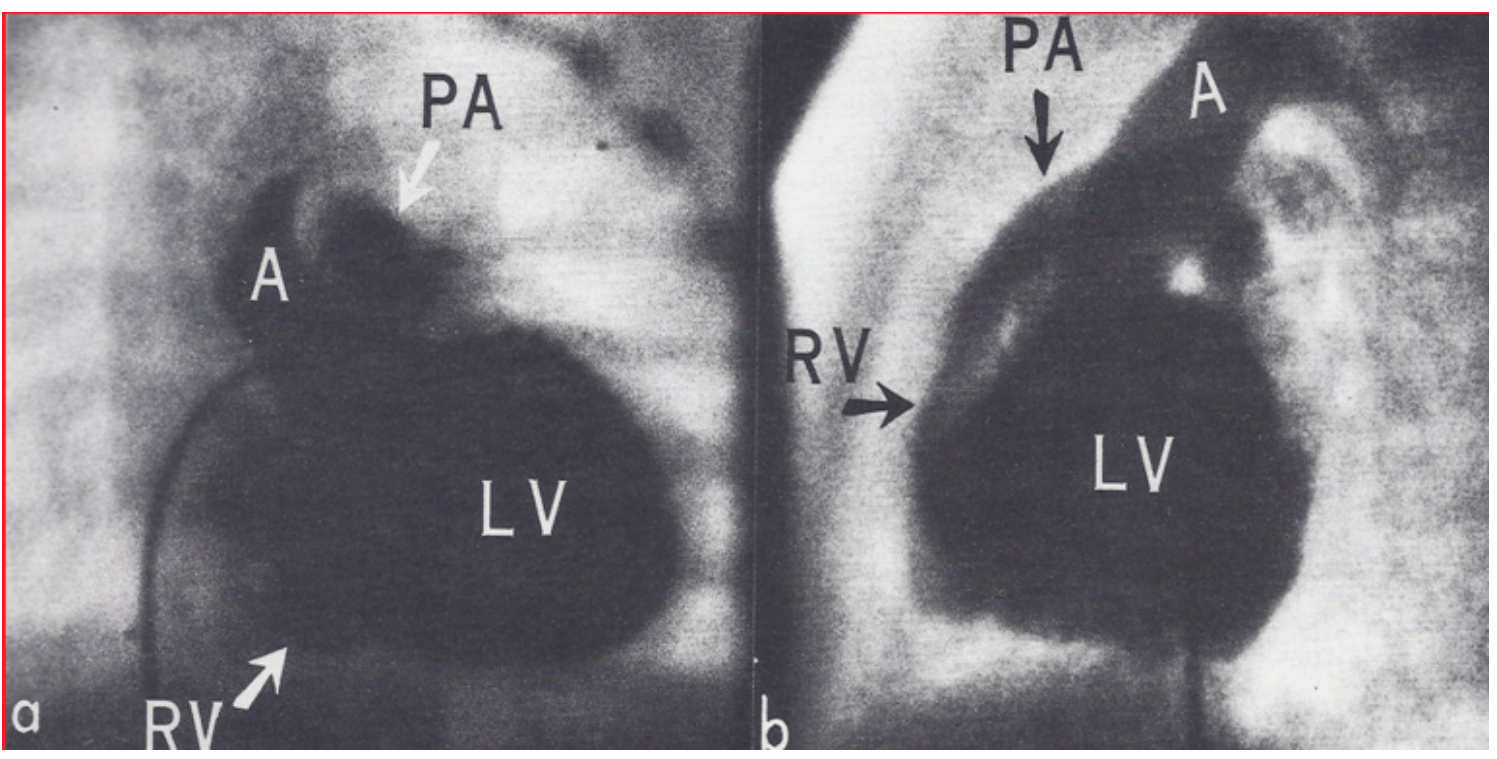

Figure 1: a) Selective left ventricular (LV) cineangiogram in antero-posterior and b) Lateral views at the age 5.5 months, demonstrating opacification of the right ventricle (RV) via a ventricular septal defect (not labeled) [2].

A: Aorta; PA: Pulmonary Artery

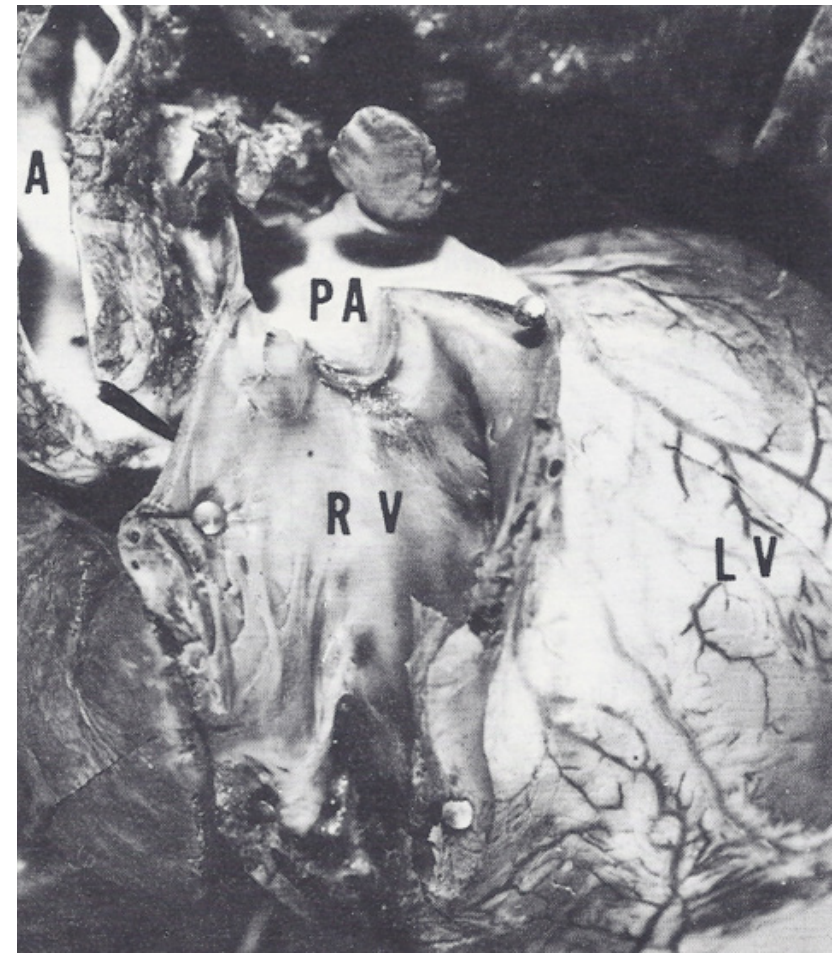

Figure 2: Photograph of the heart with the right ventricle (RV) open at autopsy at the age of 2.5 years, demonstrating no evidence of the previously seen (Figure 1) ventricular septal defect [2].

A: Aorta; PA: Main pulmonary artery

ventricle, spontaneous closure of VSDs was observed in patients with tetralogy of Fallot, pulmonary atresia with VSD and transposition of the great arteries with intact atrial septum, and double inlet left ventricle with ventriculo-arterial discordance [15-17].

\section{Tricuspid Atresia}

The interest of the author in the phenomenon of

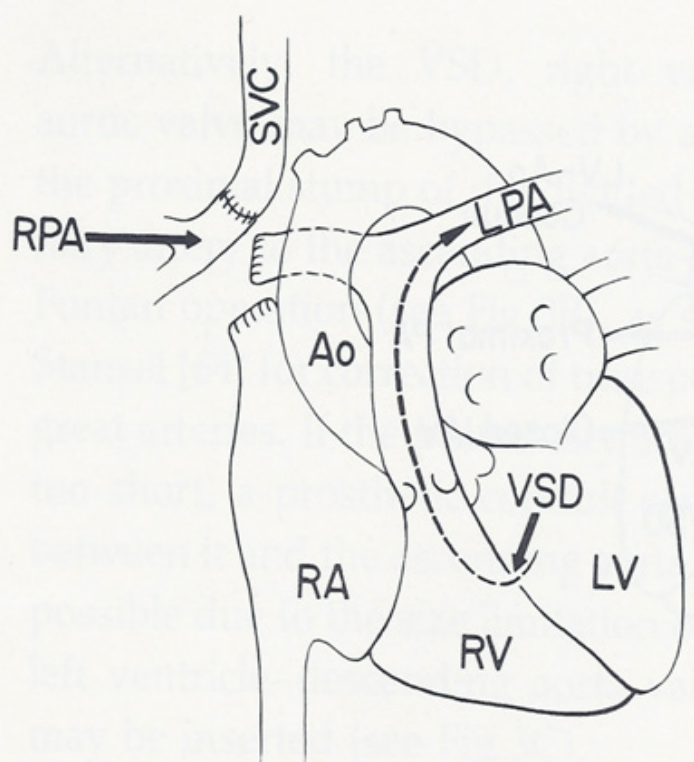

Figure 3: Line drawing of classic Glenn anastomosis connecting the superior vena cava (SVC) with the right pulmonary artery (RPA). Should the ventricular septal defect (VSD) close spontaneously, the left pulmonary artery (LPA) will be without blood flow [13].

Ao: Aorta; LV: Left Ventricle; RA: Right Atrium; RV: Right Ventricle

spontaneous closure of physiologically advantageous VSDs resulted in examining this issue in patients with tricuspid atresia [9-14]. While studying these issues, the author's interest in other features of tricuspid atresia emerged. The ensuing investigations resulted in the publication of a number of papers and book chapters [18-32] including two books [33,34]. In this section of the book, terminology [35-37]; unified classification (Figure 5 and Figure 6) [38-40]; description of rare types 


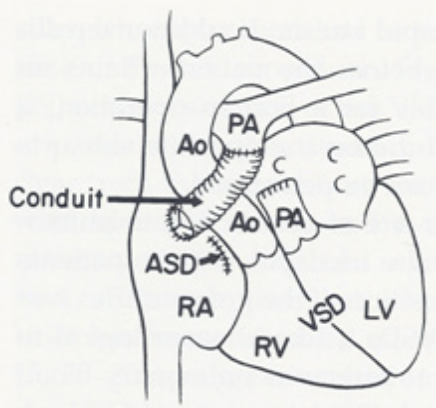

A

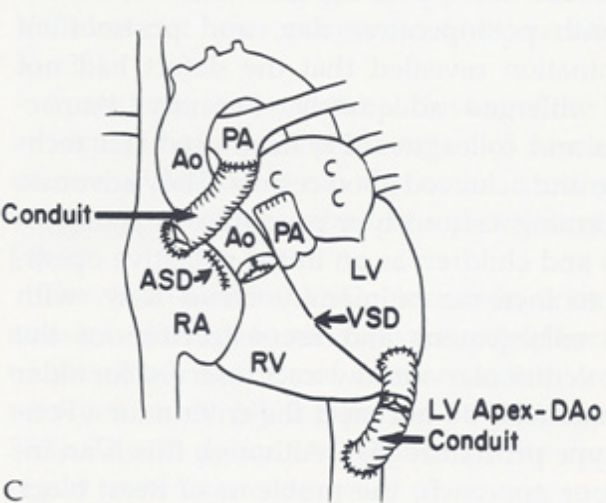

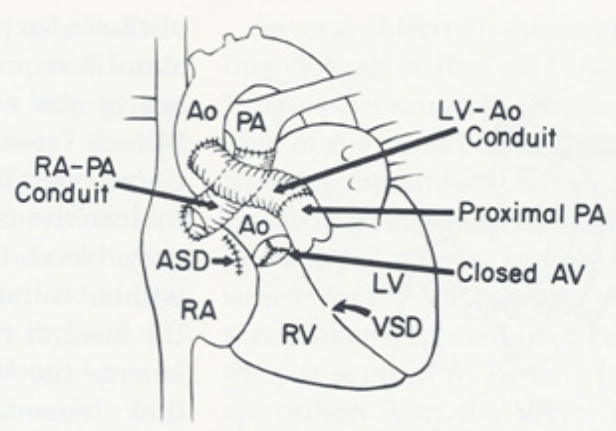

B

Figure 4: A) Line drawing illustrating atrio-pulmonary type of Fontan for patients with tricuspid atresia with transposition of the great arteries. The left ventricular (LV) blood flows via the ventricular septal defect (VSD) and right ventricle (RV) into the aorta (Ao); B) If the VSD is small and restrictive, causing "subaortic" obstruction, this obstruction may be bypassed by connecting the proximal stump of the divided pulmonary artery (PA) to the Ao directly or via a non-valved conduit; C) An alternate approach is to connect the LV apex to the descending aorta (DAo) $[10,13]$.

ASD: Atrial Septal Defect; RA: Right Atrium

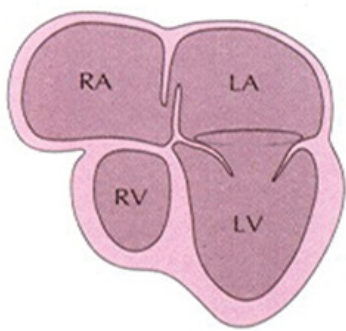

A. Muscular

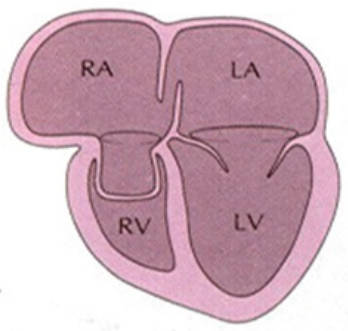

D. Ebstein's

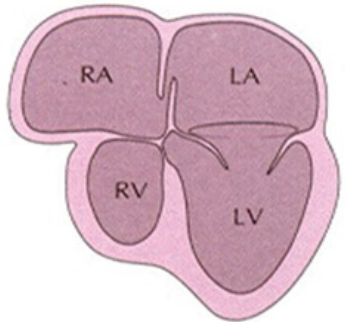

B. Membranous

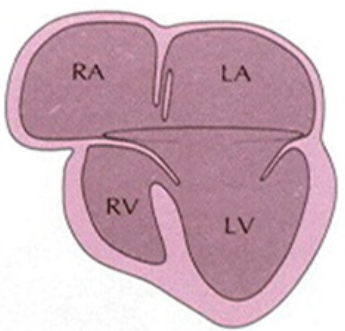

E. AV canal

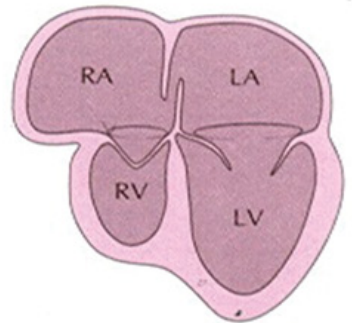

C. Valvular

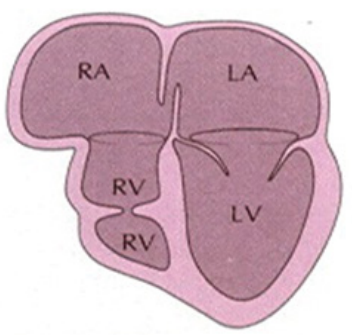

F. Unguarded with muscular shelf

Figure 5: A) Classification based on morphology of the tricuspid valve is shown diagrammatically. The classic muscular type is shown with a thick band of tissue where the tricuspid valve should be; B) Membranous type; C) Valvular type with fused valve leaflets; D) Ebstein's type with fused valve cusps along with Ebstein type of downward displacement of the tricuspid valve; E) Atrioventricular (AV) canal (septal) type with common AV leaflet sealing off the right ventricle (RV) from the right atrium (RA) and F) Unguarded muscular shelf type where the RV is divided into inlet and outlet portions by a muscular shelf [19].

LA: Left Atrium; LV: Left Ventricle 


\section{UNIFIED CLASSIFICATION OF TRICUSPID ATRESIA}

Type I Normally related great arteries

Type II D-transposition of the great arteries

Type III Malpositions of the great arteries other than D-transposition

Subtype 1: L-transposition of the great arteries

Subtype 2: Double-outlet right ventricle

Subtype 3: Double-outlet left ventricle

Subtype 4: D-malposition of the great arteries (anatomically corrected)

Subtype 5: L-malposition of the great arteries (anatomically corrected)

Type IV Persistent truncus arteriosus

Each type and subtype are divided:

Subgroup a: Pulmonary atresia

Subgroup b: Pulmonary stenosis or hypoplasia

Subgroup c: Normal pulmonary arteries (no pulmonary stenosis)

Figure 6: Unified classification based on associated cardiac defects [19,38].
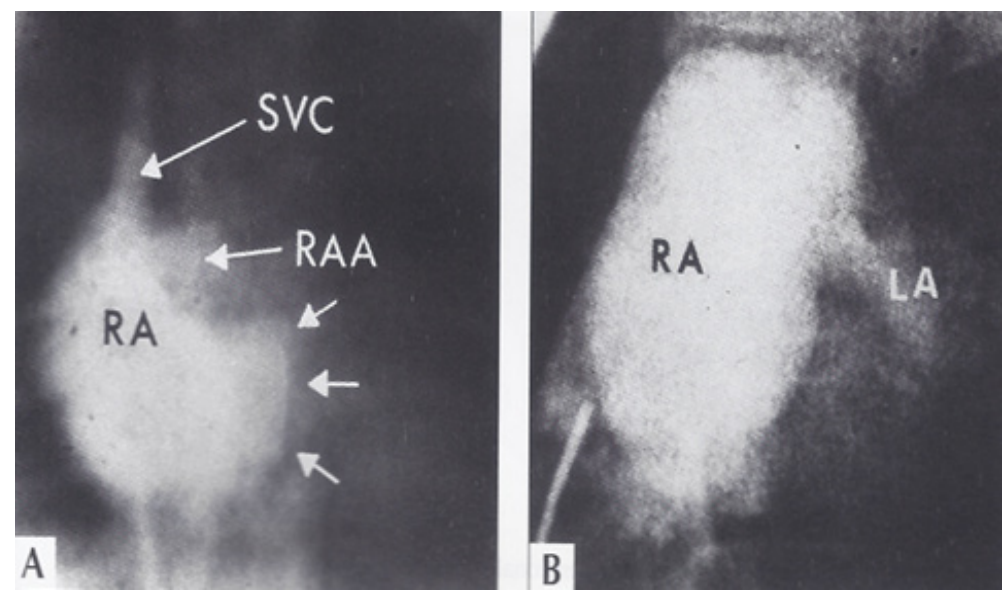

Figure 7: A) Selected right atrial (RA) cineangiographic frame in postero-anterior view prior to opacification of the left atrium (LA) in a patient with tricuspid atresia with Ebstein's malformation. The contrast material delineates the atretic tricuspid valve and is shown by small unlabelled arrows. This is rounded and extends more to the left than in other tricuspid atresia cases; B) Right atrial angiographic frame from a patient with classic tricuspid atresia is shown for comparison with figure A. This frame is frozen prior to full opacification of the LA [41].

RAA: Right Atrial Appendage; SVC: Superior Vena Cava
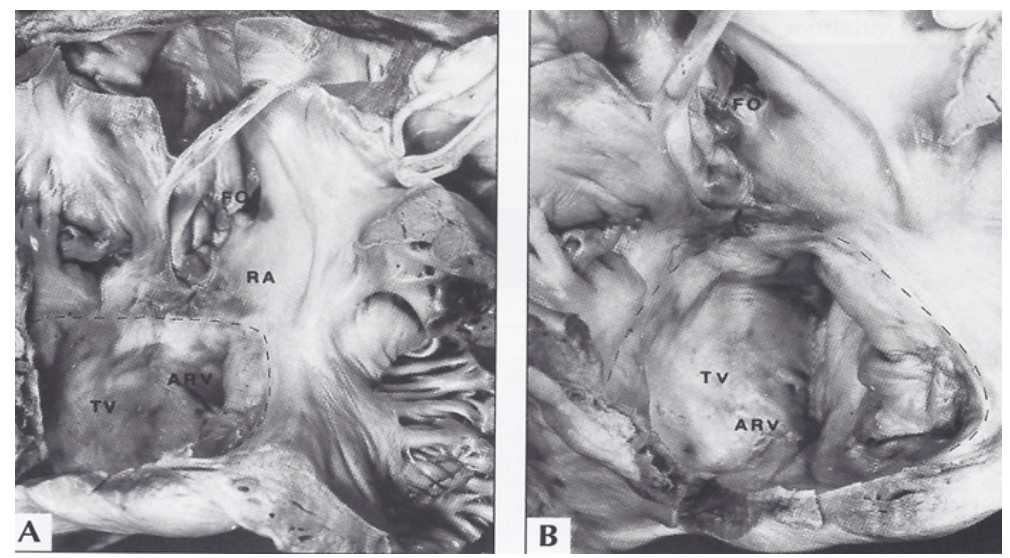

Figure 8: A) The interior of the right atrium and of the atrialized right ventricle (ARV) in a patient with tricuspid atresia with Ebstein's malformation are shown. B) This is a close-up of A. The interrupted line demarcates the true tricuspid valve annulus. The tricuspid valve (TV) leaflets are displaced downward (Ebstein's malformation) and fused, incorporating a part of the right ventricle into the right atrium (RA) [41].

FO: Fossa Ovalis 

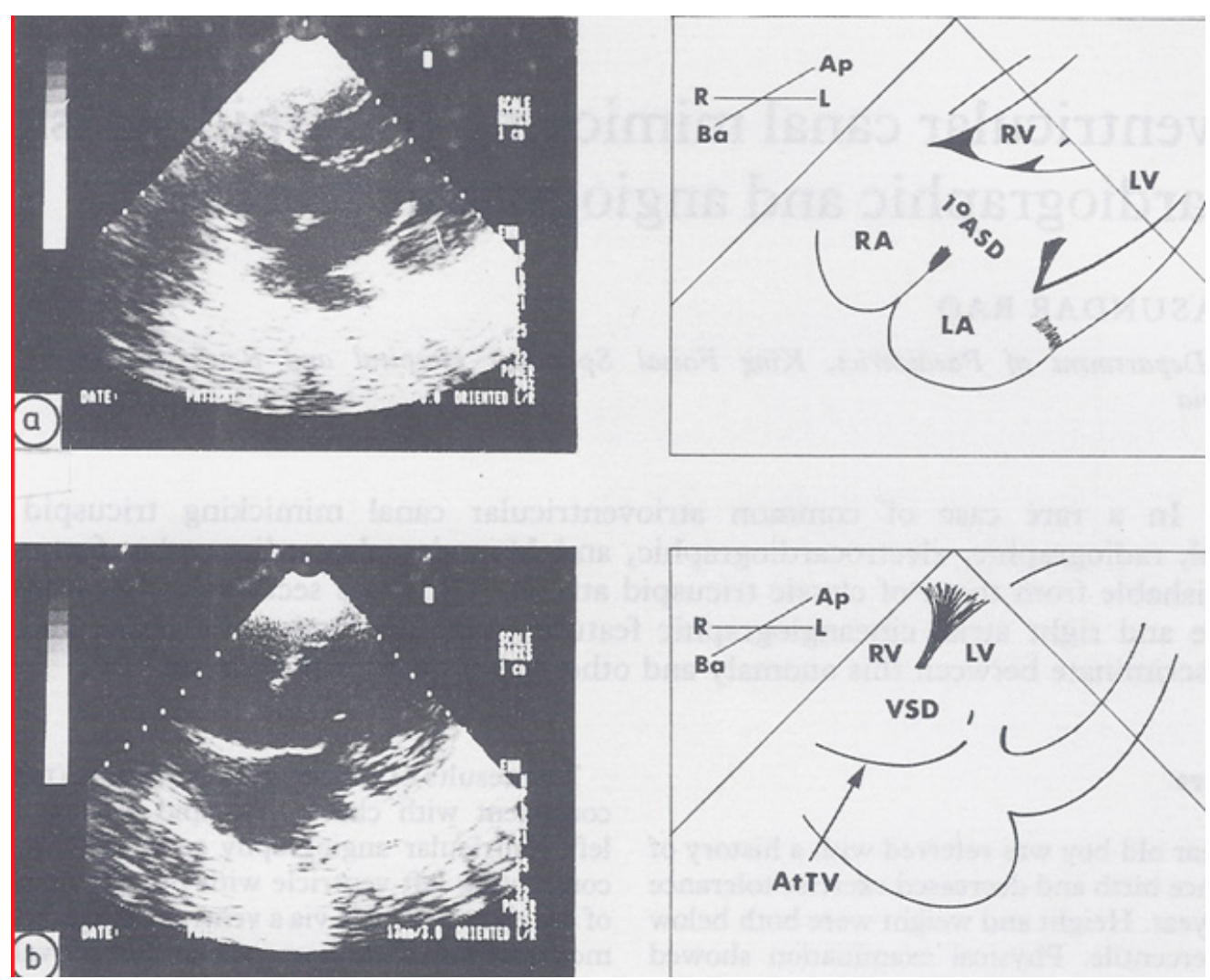

Figure 9: Selected two-dimensional, subcostal, four-chamber echocardiographic frames with an open (a) and closed (b) atrioventricular valve. Line drawings on the right of $a$ and $b$ are made for greater clarity and for labeling. A large ostium primum atrial septal defect $\left(1^{\circ} \mathrm{ASD}\right)$ is shown in a. When the large atrioventricular valve leaflet is open (a), it completely closes the right ventricle (RV) from the right atrium (RA) and the ventricular septal defect (VSD) and allows the emptying of blood from both atria into the left ventricle (LV). When the atrioventricular valve leaflet is closed (b), it continues to occlude the RV from the RA while allowing the VSD to freely communicate between the RV and LV [42].

Ap: Apex; AtTV: Atretic Tricuspid Valve; Ba: Base; L: Left; LA: Left Atrium; R: Right

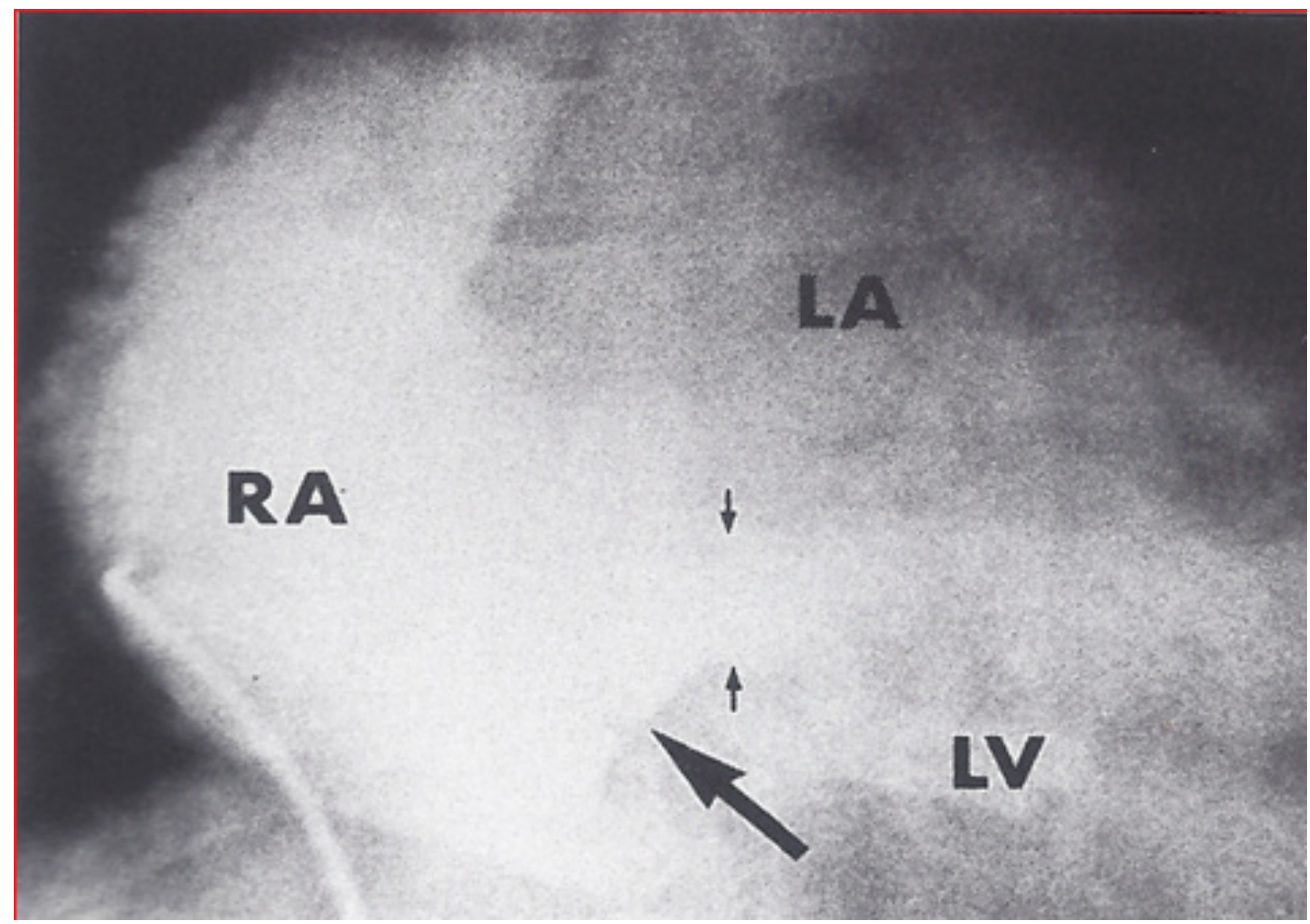

Figure 10: Selected right atrial (RA) angiographic frame in postero-anterior view, demonstrating that the floor of the right atrium is formed by one of the leaflets of the atrioventricular valve; this is marked by a large arrow. The contrast material exited the RA via an ostium primum atrial septal defect, shown by small arrows, with subsequent opacification of the left ventricle (LV) [42].

\section{LA: Left Atrium}


of tricuspid atresia (Figure 7, Figure 8, Figure 9, Figure 10, Figure 11 and Figure 12) [41-44]; were reviewed.

Also discussed were: enumeration of demographic $[45,46]$, electrocardiographic [47-49], and echocardiographic features [50-52]; description of new findings of left to right atrial shunt in tricuspid atresia (Figure 13 and Figure 14) [53]; cardiac catheterization [54,55]; principles of palliation [56,57]; role of percutaneous interventions [58,59]; and insights into surgical approaches [60-62].

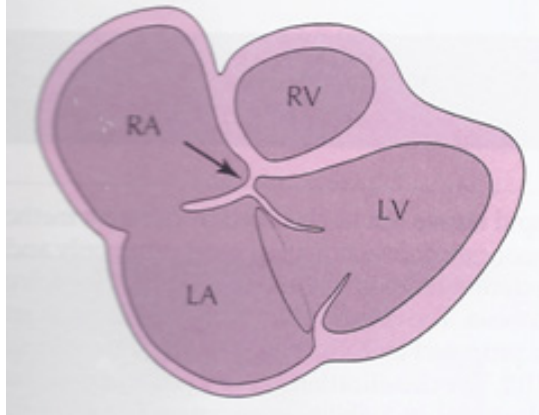

A. Muscular

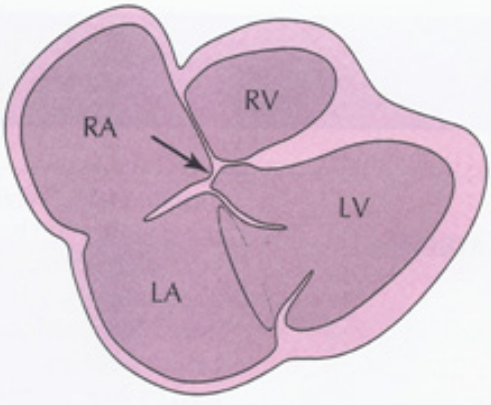

B. Membranous

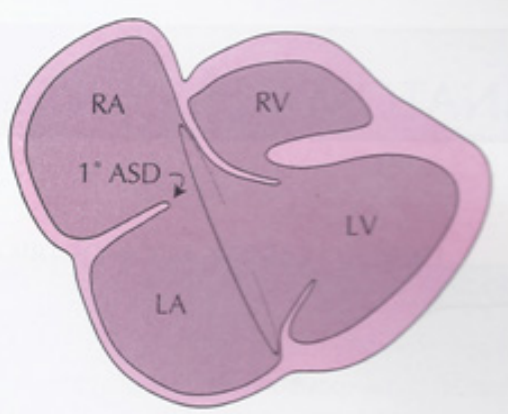

C. AV canal

Figure 11: Line drawings demonstrating two-dimensional echocardiographic appearances in a subcostal four-chamber view of the muscular (A), membranous (B) and atrioventricular canal (C) variants of tricuspid atresia. A) The atretic tricuspid valve is represented by a thick band of echoes between the right atrium (RA) and the small right ventricle (RV) in the muscular type; $B$ ) The tricuspid valve is represented by a thin line in the membranous type. Note that crux of the heart (arrows in $A$ and $B$ ) is clearly seen in both these types ( $A$ and $B$ ). The attachment of the anterior leaflet of the detectable atrioventricular valve to the left side of the interatrial septum is evident; C) In the atrioventricular canal type of tricuspid atresia, the anterior leaflet of the detectable atrioventricular canal is attached to the anterior wall of the heart, occluding the right ventricle from the right atrium, and allows the exit of blood from both atria into the left ventricle (LV). The crux cordis and the atrioventricular portion of the inter-ventricular septum are not seen $[19,42]$.
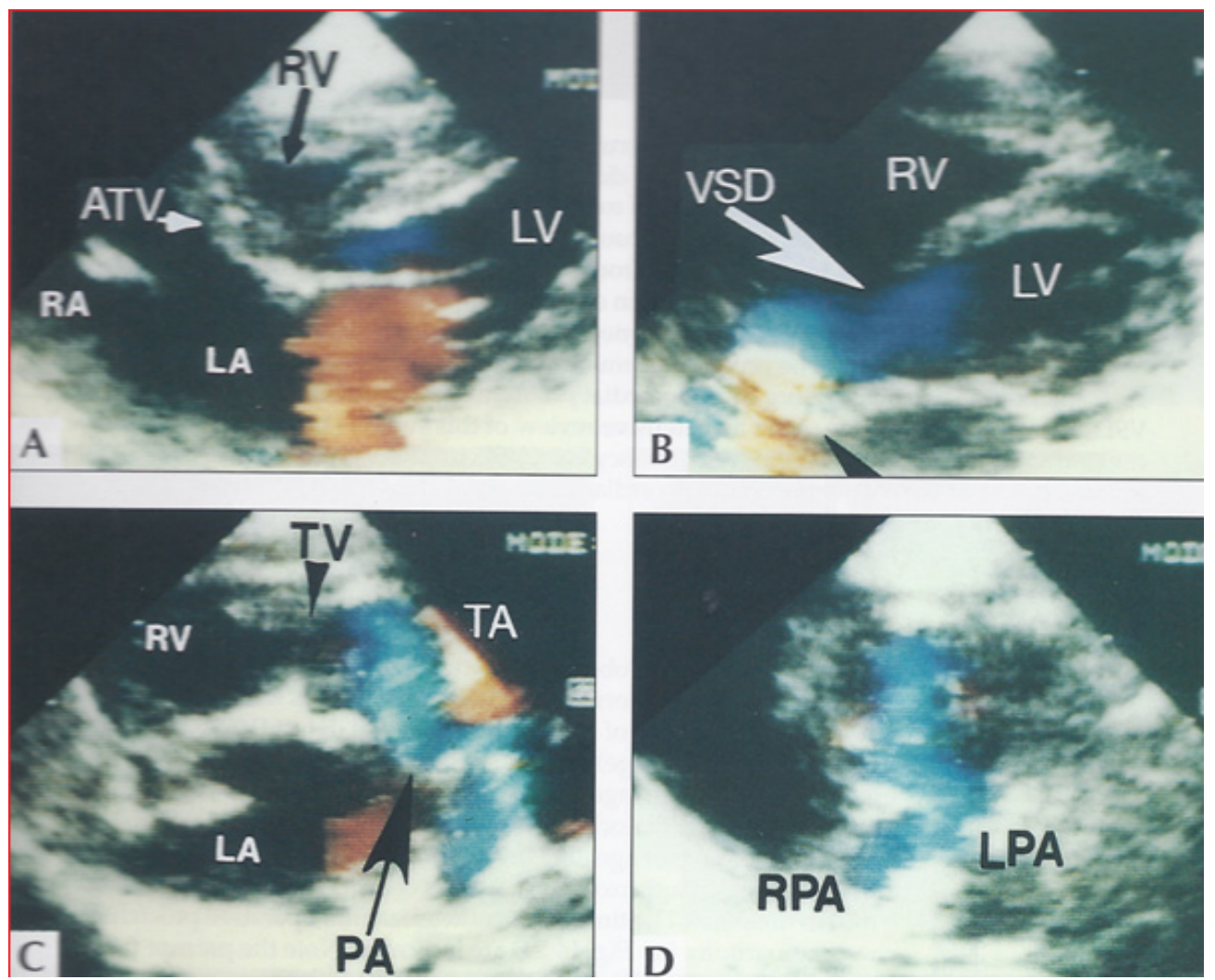

Figure 12: Selected video frames from a two-dimensional echocardiographic and color Doppler study demonstrating a) An atretic tricuspid valve (ATV) between the right atrium (RA) and right ventricle (RV) and blood flow from the left atrium (LA) into the left ventricle (LV) across the mitral valve. The RV (arrow) is very small and hypoplastic; b) LV and RV with a large ventricular septal defect (VSD) below the truncus arteriosus (TA). Turbulent flow across the truncal valve suggests truncal valve stenosis; c) The origin of the pulmonary artery (PA) from the TA by color flow (arrow), and d) The division of right (RPA) and left (LPA) pulmonary arteries from the PA (not labeled in d) in a short-axis view [43].

TV: Truncal Valve Leaflets 


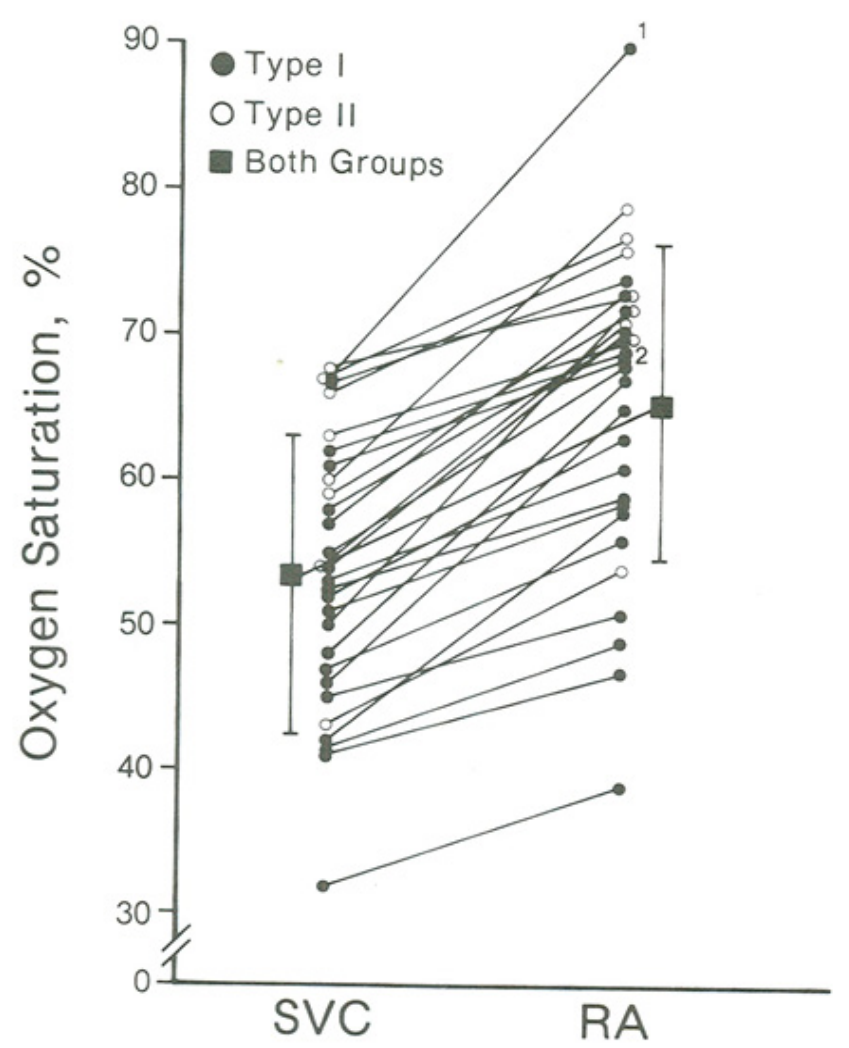

Figure 13: Oxygen saturation data of tricuspid atresia patients with left-to-right shunt. The superior vena caval (SVC) and the right atrial (RA) saturations in \% are shown. Each saturation is marked as closed circles in Type I (normally related great arteries) patients and as open circles in Type II (transposition of the great arteries) patients. There is a statistically significant $(p<001)$ increase in oxygen saturation from the SVC to RA (square). The magnitude of the increase in shunt between Type I and Type II patients is not significant ( $p>0.1)$ (not shown) [53].

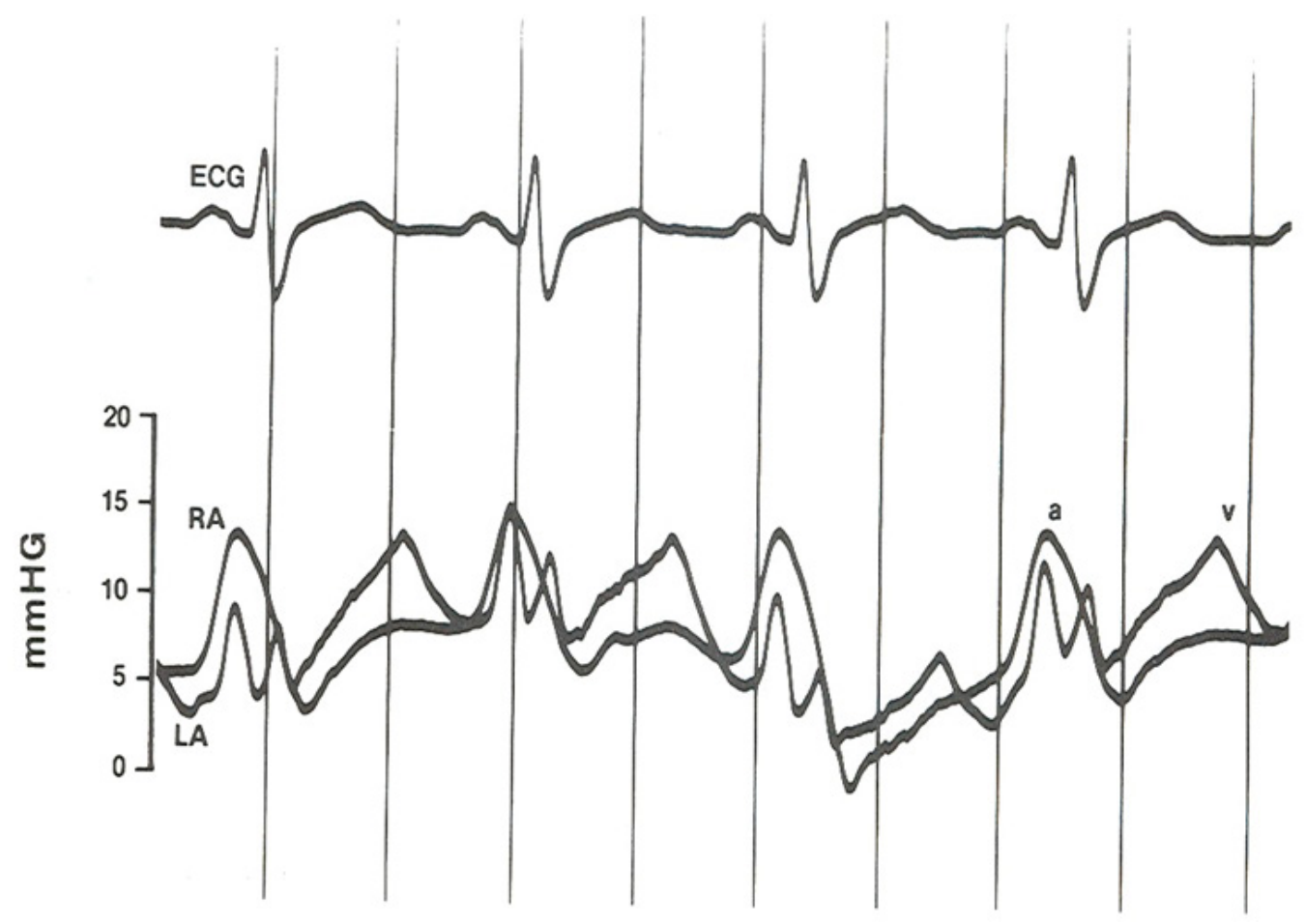

Figure 14: Pressure tracings from the left atrium (LA) and right atrium (RA) recorded simultaneously via high fidelity miniature transducers mounted within the catheter $5 \mathrm{~cm}$ apart, one placed in the LA and the other in the RA. These tracings demonstrate higher pressure in the RA than the LA during atrial systole (a wave) and lower pressures in the RA than LA during atrial diastole ( $v$ wave); the later may have been responsible for the left-to-right shunt. It may be concluded that these instantaneous pressure differences between atria are likely to explain the left-to-right shunt in tricuspid atresia [53]. 


\section{Management of Cyanotic Congenital Heart Defects}

Management of cyanotic congenital heart defects (CHDs) was detailed. Whereas the need for addressing the acyanotic CHD patients is to a great degree dependant on the severity of the lesion, the majority of cyanotic CHDs need intervention, typically by a variety of surgical procedures. At first, the pathophysiological consequences of cyanotic CHD were reviewed [63]. Then, the discussion of general management cyanotic CHDs $[64,65]$. This is followed by a brief description of each of these cyanotic CHDs and then their management.

Different types of tetralogy of Fallot (TOF) babies necessitate different types of surgical procedures [6568]. Most of conventional TOF infants are either acyanotic or minimally cyanotic at birth and may not need surgical intervention in the neonatal period. Hyper cyanotic spells may occur in TOF patients, mostly during infancy. The possible etiology and management of these spells were described $[63,66,68]$. Total surgical correction involves closure of VSD allowing the left ventricle (LV) pumping into the aorta, and alleviating the infundibular, valvar and pulmonary artery obstruction with or without trans-annular patch, all under cardiopulmonary bypass; this is generally undertaken between three to 12 months of age. Pulmonary valve-sparing surgery is more frequently performed at the present time. Some of these babies may need initial palliation, mostly by a modified BT shunt. Some babies may be benefitted by balloon pulmonary valvuloplasty in place of modified BT shunts to augment the pulmonary blood flow.

The early management of TOF with pulmonary atresia who are ductal dependent is by prompt intravenous administration of $\mathrm{PGE}_{1}$ to keep the ductus open. After the infant is stabilized, a stable way to provide pulmonary blood flow should be instituted. In infants whose defects cannot be completely corrected in the newborn period, a modified BT shunt using an interposition Gore-Tex graft between right or left subclavian artery and the ipsilateral pulmonary artery is current surgical procedure of choice. Ductal stents are used at some institutions instead. Total surgical correction with closure of VSD and pulmonary valvotomy with or without trans-annular patch or insertion of a right ventricle to pulmonary artery valved conduit (usually a homograft) under cardio-pulmonary bypass is performed when the baby is between six and twelve months of age $[65,67,69-71]$.

The initial treatment of babies with TOF with multiple aorto-pulmonary collateral arteries (MAPCAs) is dependent on the degree of pulmonary blood flow $[65,67,72,73]$. Most of the patients will maintain satisfactory arterial oxygen saturations, usually between $80 \%$ to $90 \%$ and may not need intervention as a neonate. Babies with reduced pulmonary flow and hypoxemia may require $\mathrm{PGE}_{1}$ and $\mathrm{BT}$ shunt. Babies with increased pulmonary flow require anti-congestive management. The ultimate treatment of TOF with MAPCAs encompasses combined staged approach with surgical and catheter interventional procedures to institute anterograde pulmonary blood flow from the right ventricle, re-establish the pulmonary arteries by unifocalization types of procedures, and closure of the VSD $[65,67,72,73]$.

Symptomatic newborn babies with TOF and syndrome of absent pulmonary valve need ventilatory support to stabilize the patient; this is followed by total surgical correction using cardiopulmonary bypass. Closure of the VSD, relief of PS by a trans-annular pericardial patch as needed, and partial resection and plastic repair of aneurysmally dilated pulmonary arteries are undertaken $[65,67,74]$.

Infants with transposition of the great arteries with intact ventricular septum as well as the babies with VSD require arterial switch (Jatene) operation whereas babies with both VSD and pulmonary stenosis (PS) are managed with Rastelli procedure [65-68,75]. These surgical procedures may have to be preceded by prostaglandin infusion and/or balloon atrial septostomy in some infants $[65-68,75]$. Babies with tricuspid atresia need palliative intervention either with a modified BT shunt or banding of the pulmonary artery, as the case may be with subsequent staged Fontan correction consisting of bidirectional Glenn and fenestrated Fontan with extra-cardiac conduit $[26,28,62,65]$. Infants with total anomalous pulmonary venous connection are treated by anastomosing the common pulmonary venous confluence with the left atrium either electively in non-obstructed types or as an emergent surgery in the obstructed varities $[65,73,76,77]$. Infants with truncus arteriosus are managed wit surgical intervention which includes closure of VSD coupled with right ventricle to pulmonary artery conduit $[65,76,78-80]$.

The medical and surgical treatment of other CHDs, namely, hypoplastic left heart syndrome [72,73,81], pulmonary atresia with intact ventricular septum $[65,69,72,73,81,82]$, double-outlet right ventricle $[65,76,83]$, univentricular hearts including double-inlet left ventricle $[17,34,65,72,76]$, corrected transposition of the great arteries [65,84-86], Ebstein's anomaly of the tricuspid valve $[65,85,87-89]$, pulmonary atresia without intact ventricular septum (with VSD) $[17,34,65,72,76,84$ 86], mitral atresia with normal aortic root $[34,65,90,91]$, interrupted aortic arch [65,92], and dextrocardia and heterotaxy syndromes (asplenia and polysplenia) [65,9396] was also discussed. The presently used medical, trans-catheter and surgical procedures to treat cyanotic CHD are safe and effective and can be performed at a fairly low risk.

\section{Adult Congenital Heart Disease}

The contributions of the author with regard to 
adult CHD issues, namely infective endocarditis, transcatheter closure of PDA, trans-catheter occlusion of ASDs, trans-catheter closure of ASD/PFO for prevention of recurrence of paradoxical embolism, closure of ASDs/PFOs with right-to-left shunt in children who had prior cardiac surgery, percutaneous closure of aorto-pulmonary window, trans-catheter management of platypnea-orthodeoxia syndrome, and balloon dilatation of CoA, PS, and aortic stenosis in adults were discussed and referenced in Parts I and II of the book summary and will not be repeated. Then, a discussion of "What an adult cardiologist should know about cyanotic CHD" was presented $[97,98]$. The prevalence of CHDs in adult subjects has increased during the last two decades such that there are more adults with CHD than children at this time. Advances in the diagnosis and treatment of CHD during infancy and childhood seem to be the reason for this phenomenon. Most of these patients are likely to be those who previously had corrective or palliative surgery during infancy and childhood, though rarely uncorrected CHDs may present in adulthood. Pathophysiologic effects of right to left shunt associated with cyanotic CHD were discussed. Brief narrative of the anatomy of the most common cyanotic CHDs such as tetralogy of Fallot, transposition of the great arteries, truncus arteriosus, total anomalous pulmonary venous connection and tricuspid atresia was reviewed and their management. The nature of the residual defects, their long-term effects and management strategies for each of the above CHDs during adulthood were addressed.
Adults who did not have surgical correction in childhood should have surgical correction; however, there is a higher risk for surgery than that seen in children $[97,98]$.

\section{Miscellaneous Topics}

This section addresses miscellaneous topics that could not be included in the earlier sections of the book. These topics, namely, cor pulmonale as a complication following cerebral ventriculo-atrial shunts [99], physiological basis of diuretic medications [100], CHD in babies with the de Lange syndrome [101], preventive aspects of all types of heart disease in infants and children [102-106], obstruction of the superior vena cava in total anomalous pulmonary venous connection [107], early identification of the newborn with serious heart disease [108-111], infective endocarditis [112114], and utility of continuous positive airway pressure in the differential diagnosis of cardiac from pulmonary causes of cyanosis in the neonate (Figure 15) [115] were discussed.

Other topics reviewed were: polysplenia syndrome [93], present status of surgery in CHD [116,117], systematic approach to differential diagnosis of dextrocardia [93-96,118], vasodilator therapy for heart failure in pediatric practice [119-122], a new complication of chylopericardium in babies who had BT anastomosis [123-125], scimitar syndrome [126], management of syndrome of absent pulmonary valve $[74,127,128]$, mitral valve prolapse $[129,130]$,

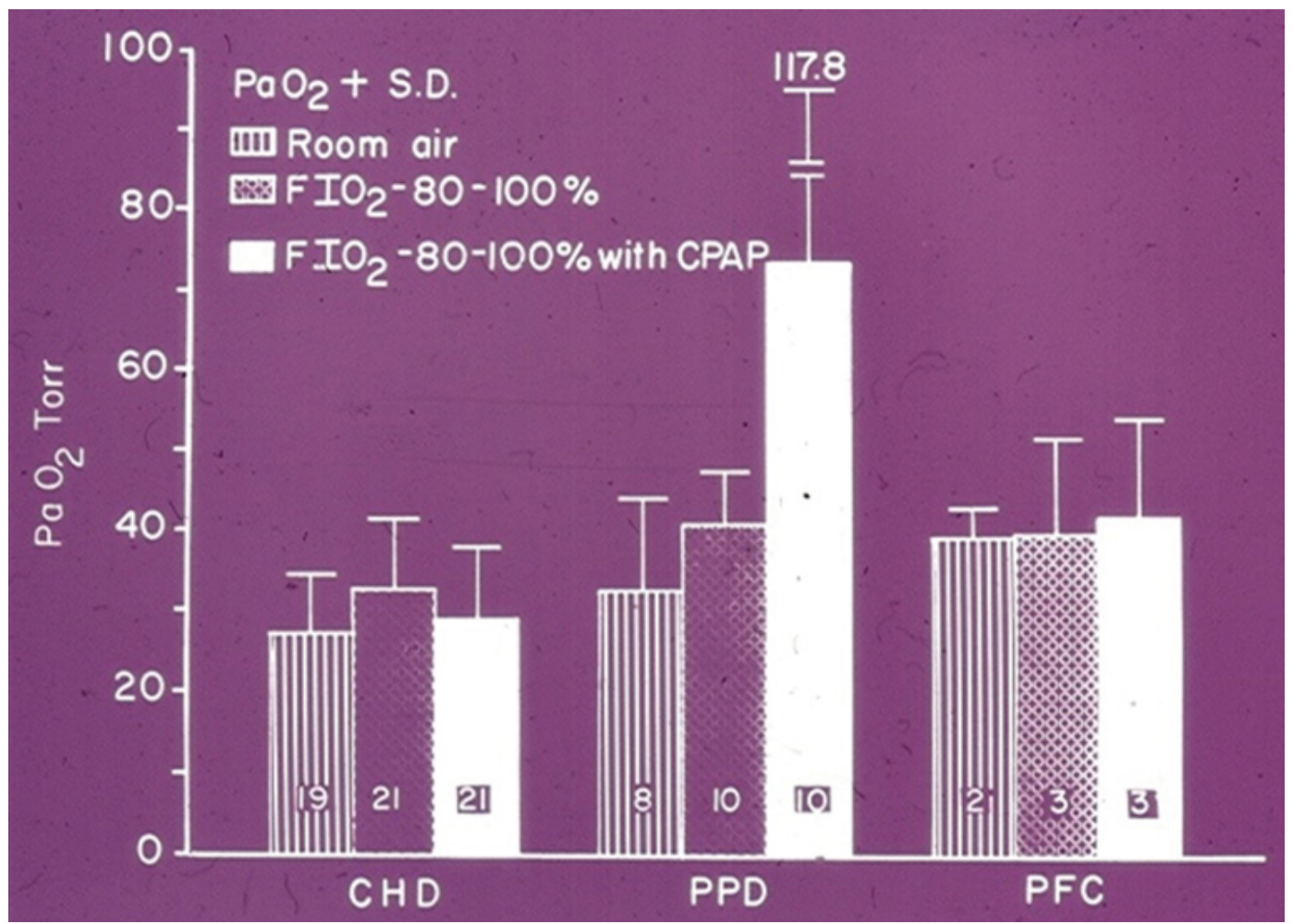

Figure 15: The $\mathrm{PaO}_{2}$ is expressed as the mean + standard deviation. The number of infants in each group is shown in each bar. There was no change in $\mathrm{PaO}_{2}$ from $\mathrm{F} 1 \mathrm{O}_{2}$ of $0.21-0.4$ to $\mathrm{F}_{10}$ of $0.8-1.0$ in all three groups. With additional CPAP the $\mathrm{PaO}_{2}$ did not change in babies with congenital heart defects (CHD) and persistent fetal circulation (PFC). However, a significant increase in $\mathrm{PaO}_{2}$ occurred in the pulmonary parenchymal disease (PD) group after CPAP [115]. 


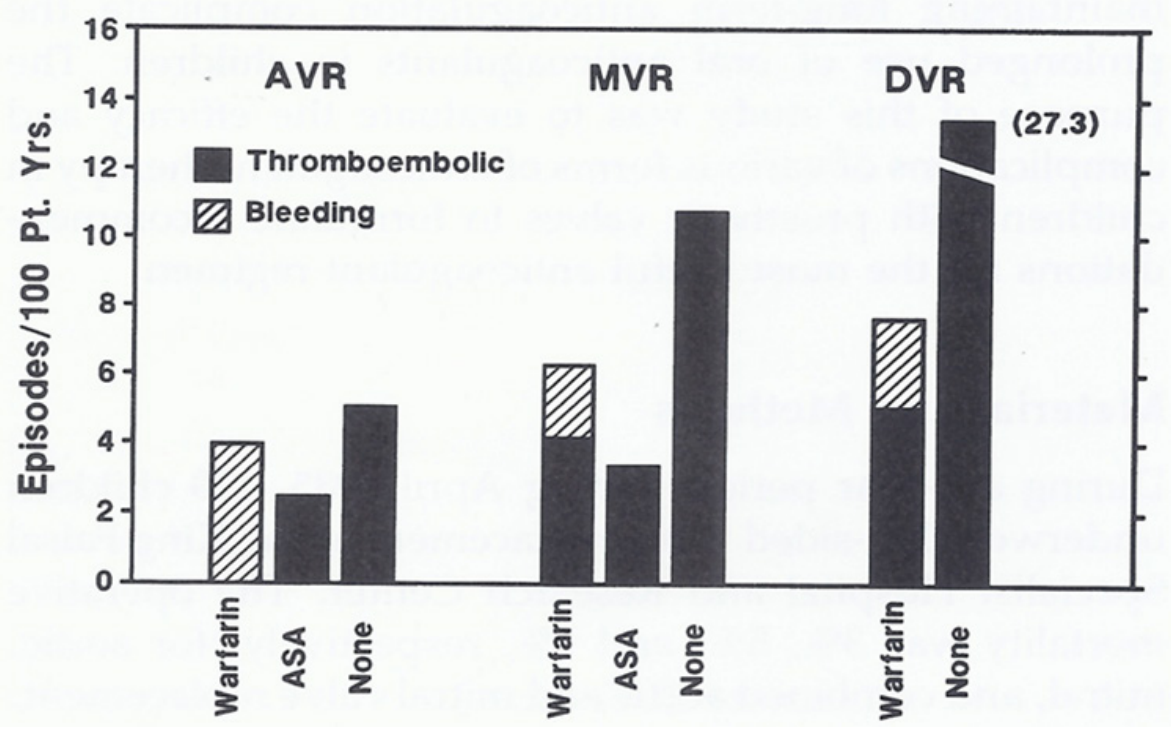

Figure 16: Thromboembolic and bleeding complications, expressed as episodes per 100 patient-years (Pt. Yrs.), based on anticoagulant treatment (warfarin sodium, aspirin plus dipyridamole [ASA], and no anticoagulants) and type of valve replacement (aortic valve [AVR], mitral valve [MVR], and double valve replacement [DVR]) [132].
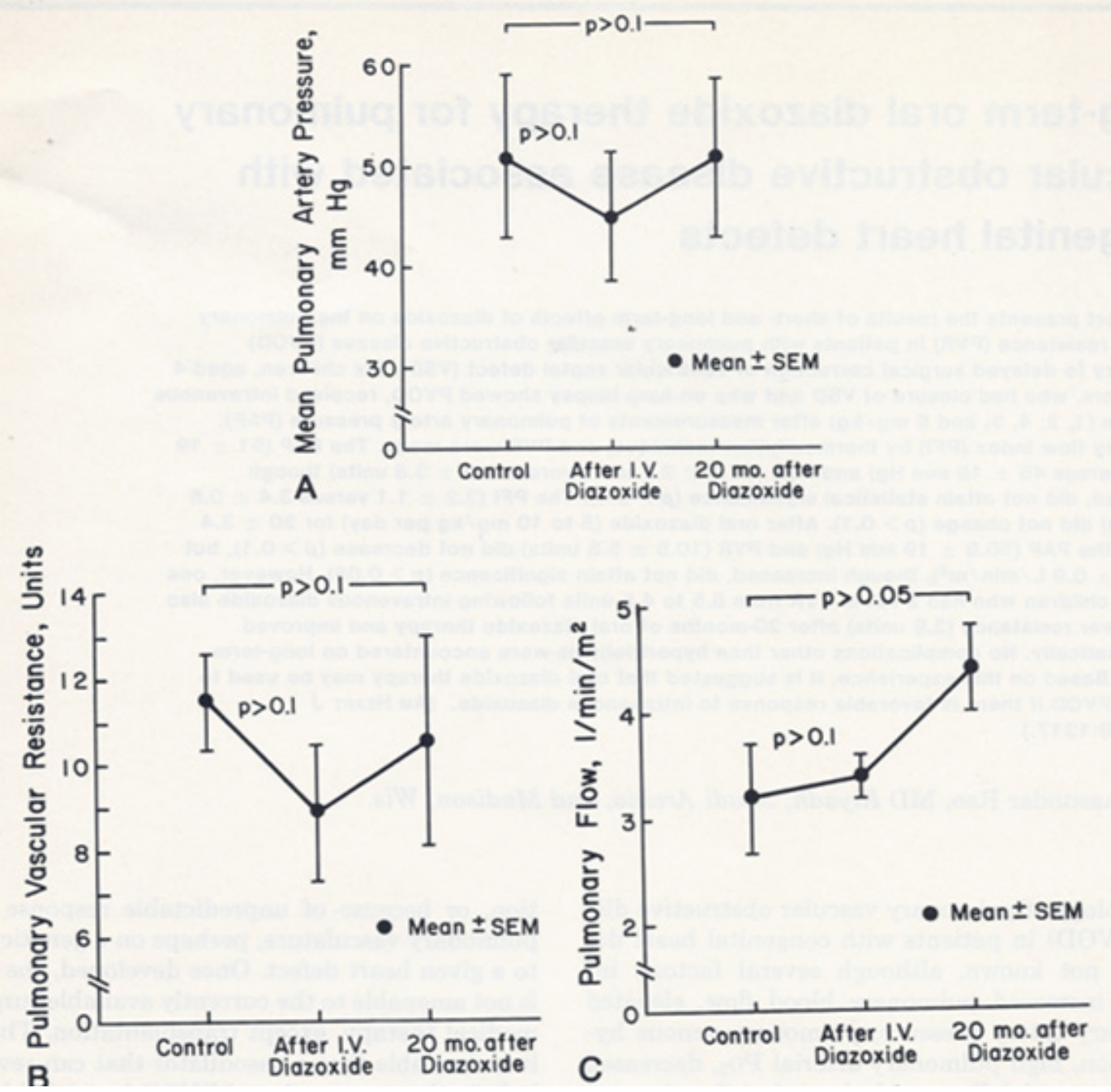

Figure 17: Response of pulmonary artery pressure (PAP), pulmonary vascular resistance (PVR), and pulmonary flow index to intravenous and long-term oral administration of diazoxide. There was a fall in the PAP (A) and PVR (B), but this did not attain statistical significance $(p>0.1)$ following intravenous administration of diazoxide (5 to $6 \mathrm{mg} / \mathrm{kg}$ ). There was no significant $(p>0.1)$ change in the pulmonary flow index $(C)$. After long-term (mean of 20 months) oral diazoxide, the PAP $(A)$ and PVR $(B)$ remained unchanged $(p>0.1)$. The pulmonary flow index increased $(C)$, although this increase was not statistically significant $(p>0.05)$ [133]. 
anticoagulant therapy in children with prosthetic valves (Figure 16) [131], long-term oral diazoxide therapy for pulmonary vascular obstructive disease associated with CHDs (Figure 17 and Figure 18) [132].
Further review of perinatal circulatory physiology [133140], prosthetic valves in children and adolescents [141], reassessment of usefulness of porcine heterografts in mitral location in children (Figure 19 and Figure 20) [142],

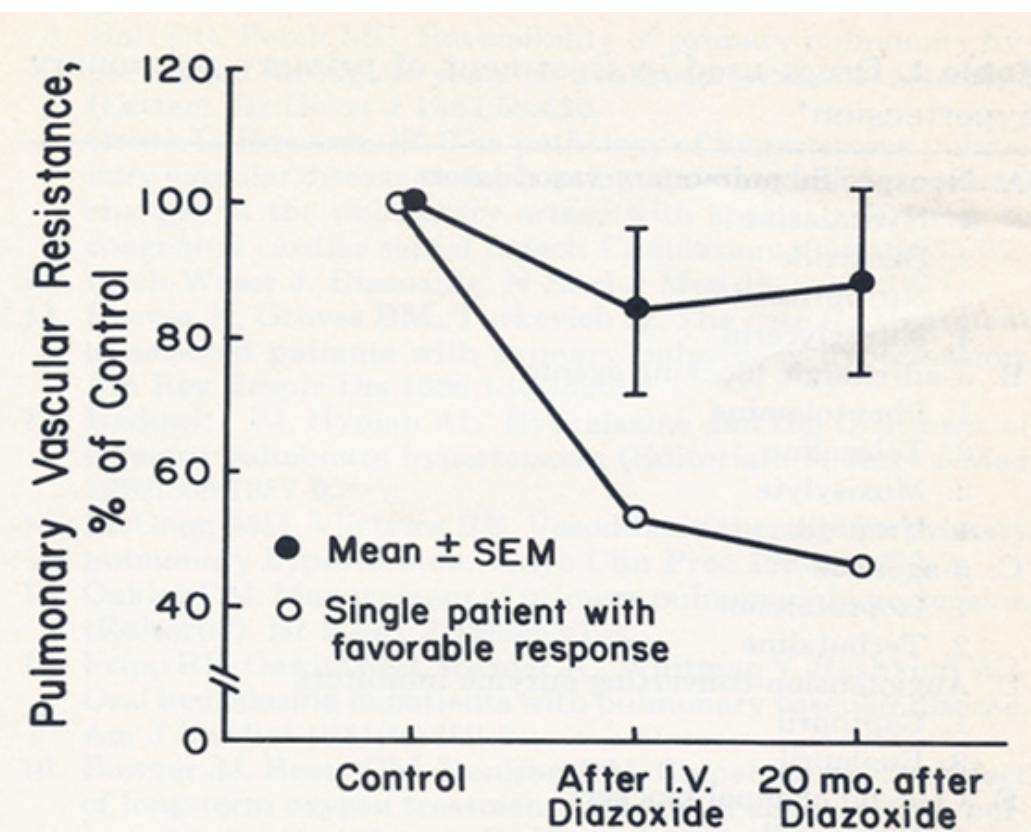

Figure 18: The percent change in the pulmonary vascular resistance (PVR) immediately following intravenous diazoxide, and after long-term oral diazoxide administration, are shown. Note that there is no significant change in the PVR for the group as a whole (solid circles). In a single patient (open circle), the PVR fell following intravenous diazoxide and remained low after 20 months of oral diazoxide therapy [133].

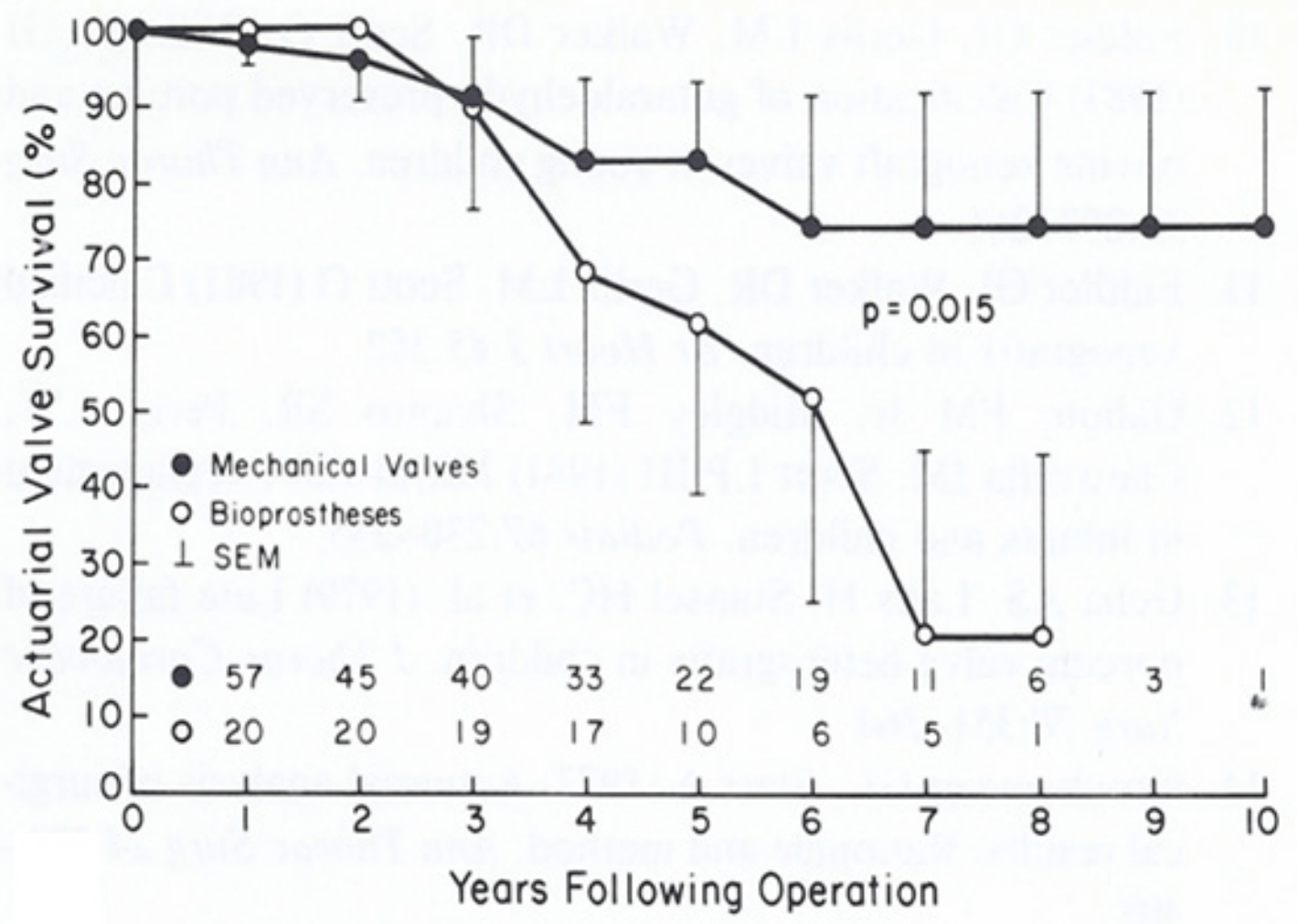

Figure 19: The actuarial valve survival curves for children $\leq 15$ years are shown for mechanical and porcine heterografts; note the poor survival rate for heterografts $(p=0.015)$. The confidence limits are marked on only one side of the curve to clearly discern both the curves [143]. 


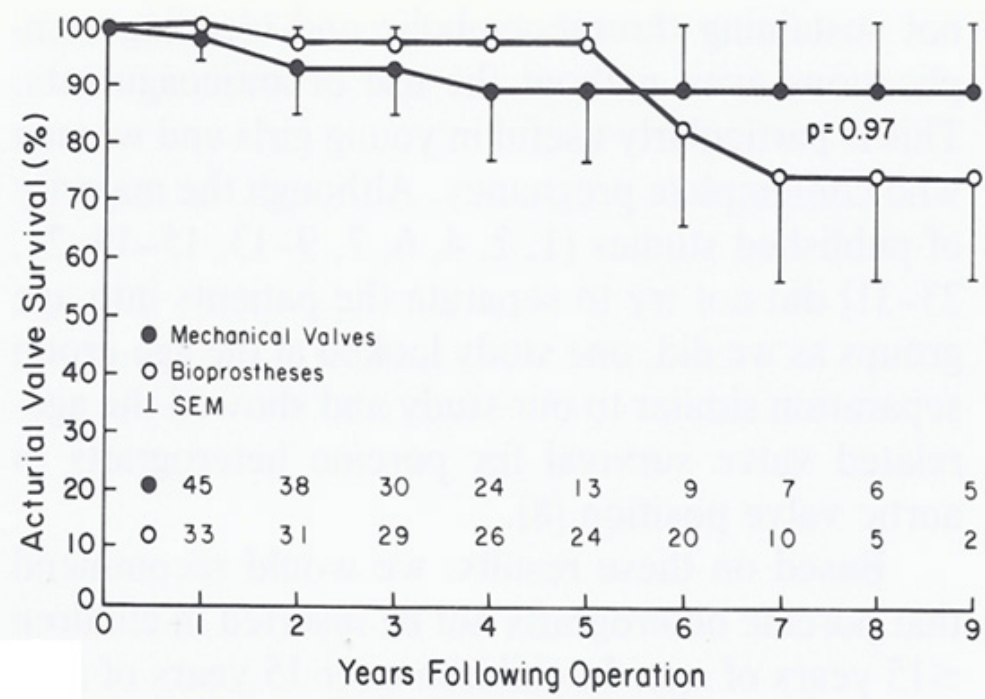

Figure 20: The actuarial valve survival curves for children $>15$ years are shown for mechanical and porcine heterografts; the survival curves are similar $(p=0.97)$. The confidence limits are marked on only one side of the curve to visualize both curves clearly [143].

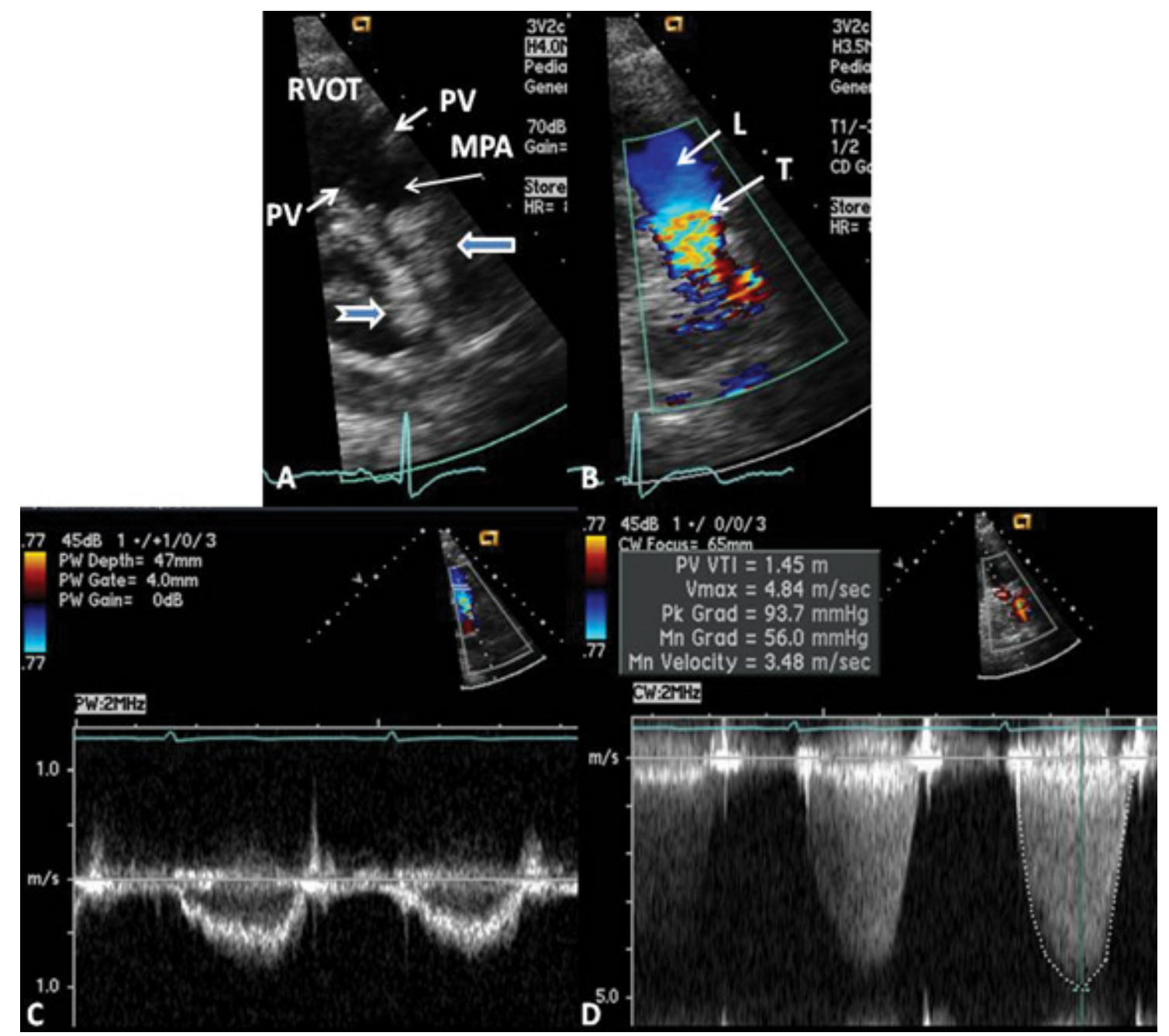

Figure 21: A) Selected video frame from a parasternal short axis view, showing echo-dense structures (thick blue arrows) within and outside the main pulmonary artery (MPA). The pulmonary valve (PV) leaflets (small arrows) are shown and appear normal. The right ventricular outflow tract (RVOT) and proximal MPA are free of any echo-dense structures; B) Color Doppler mapping of the same structures as in panel A shows normal laminar $(\mathrm{L})$ flow in the RVOT and proximal MPA and turbulent (T) flow starting in the proximal MPA, indicating obstruction; C) Pulse Doppler sampling from the proximal MPA, which shows normal flow velocity; D) Continuous wave Doppler sampling demonstrating high velocity flow across the MPA, with a calculated peak instantaneous gradient of $93.7 \mathrm{mmHg}$ and a mean gradient of $56 \mathrm{mmHg}$, indicating severe obstruction [154]. 
cardiac murmurs in children [143], delayed presentation of anomalous circumflex coronary artery arising from pulmonary artery following prior surgical repair of aortopulmonary window in infancy [144], chest pain in children [145], congenital coronary artery anomalies [146], successful thrombolytic therapy of pulmonary embolism seen in association with urosepsis in an infant [147], current perspectives on Kawasaki disease [148], an approach to the diagnosis of cyanotic neonate for the primary care provider [111], principles of management of the neonate with CHD $[110,140]$, cardiac emergencies in pediatric practice [149-152], development of supravalvar pulmonary artery stenosis following a Nuss procedure (Figure 21 and Figure 22) [153], consensus on timing of intervention for common congenital heart diseases [72,154], a review of childhood hypertension [155], prevention of sudden death in athletes [156] and state of the art management of CHDs $[73,157]$ was presented.

\section{Conclusion}

The subspecialty of Pediatric Cardiology was in early development when the author started his career in the mid-1960s. The author had the chance to observe first hand the stepwise evolution of Pediatric Cardiology over the last 50 years. Therefore, a unique historical perspective can be offered. The author has bestowed substantial interest in the development of new knowledge while providing care of patients with heart disease over a 50-year period. This book describes these developments along with the author's contributions to Pediatric Cardiology. The major focus of this book was to bring together the advances in Pediatric Cardiology, particularly the management of congenital heart defects. Along the way, the art and science of interventional pediatric cardiology were presented, as applicable to each chapter of the book.

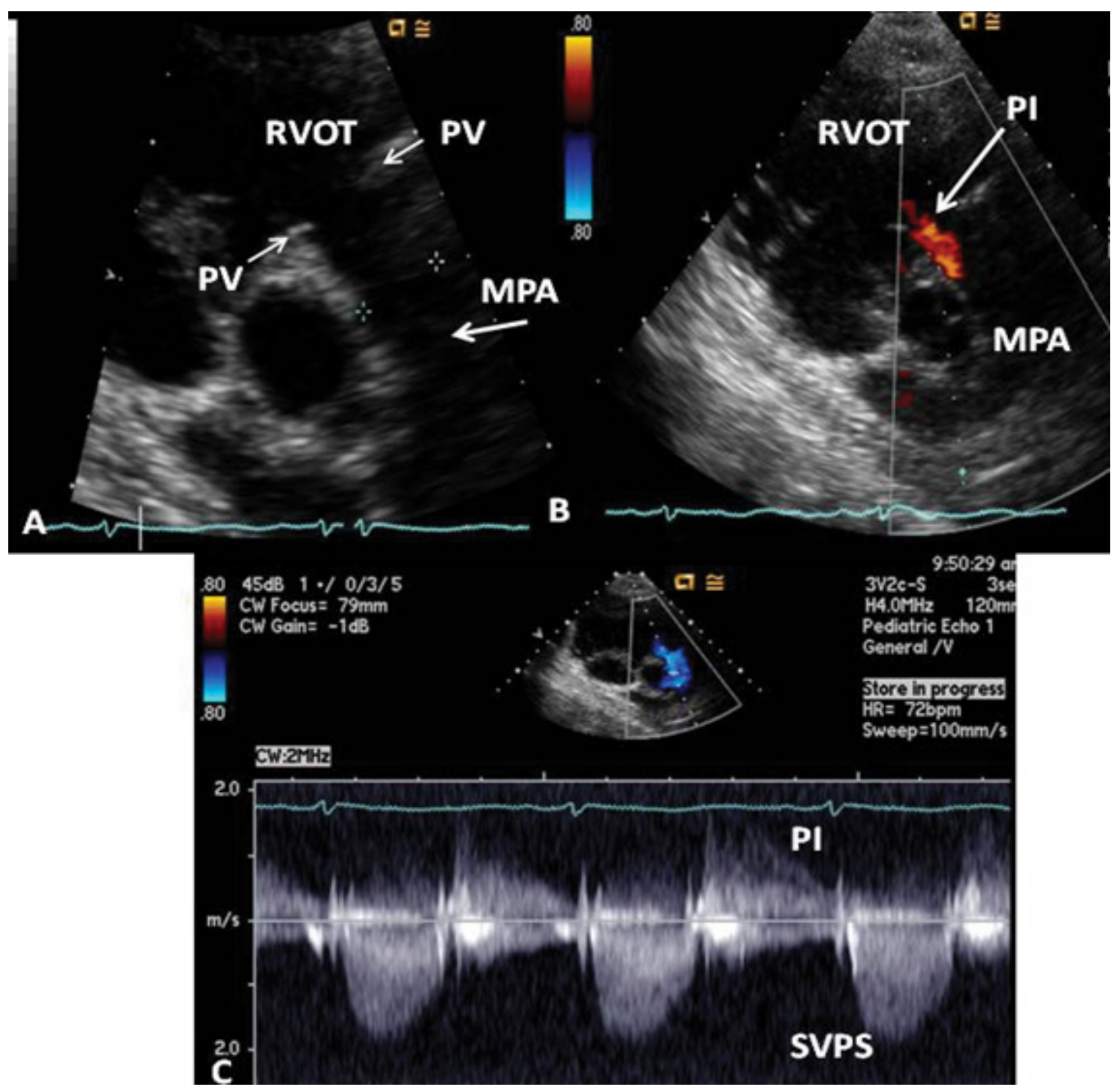

Figure 22: Echo-Doppler studies performed five months after the removal of the Nuss bar. A) Selected video frame from a parasternal short axis view, demonstrating the absence of the echo-dense structures in the right ventricular outflow tract (RVOT) and main pulmonary artery (MPA) that were seen prior to the removal of the Nuss bar (Figure 22-32A). The pulmonary valve (PV) leaflets (arrows) are shown; B) Color Doppler mapping of the same structures as in panel A, showing mild pulmonary insufficiency (PI) (arrow); C) Continuous wave Doppler sampling, demonstrating a low Doppler flow velocity across the MPA with a calculated peak instantaneous gradient of $15 \mathrm{mmHg}$, indicating minimal supravalvular pulmonary stenosis (SVPS) and mild pulmonary insufficiency (PI) [154]. 
Developments such as early detection of the neonates with serious heart disease and their rapid transport to tertiary care centers, availability of highly sensitive noninvasive diagnostic tools, advances in neonatal care and anesthesia, progress in percutaneous interventional procedures and extension of complicated surgical procedures to the neonate and infant have advanced to such a degree that almost all congenital cardiac defects can be diagnosed and "corrected". The defects that could not be corrected could be effectively palliated. Cardiac defects that were once fatal in infancy are now treatable. These principles were incorporated into the respective chapters, as applicable [1]. Although every attempt was made to minimize repetition, there was some degree of replication which was unavoidable to preserve continuity of thought and discussion. The author hopes that the information presented is useful to the medical students, residents, fellows, other trainees, and paramedical personnel as well as to the pediatricians, neonatologists, pediatric intensivists, seasoned pediatric cardiologists, and pediatric cardiovascular surgeons [1].

\section{References}

1. Rao PS (2020) Pediatric Cardiology: How it has evolved over the last 50 years. Cambridge Scholars Publishing. New Castle upon Tyne, United Kingdom.

2. Rao PS, Sissman NJ (1971) Spontaneous closure of physiologically advantageous ventricular septal defects. Circulation 43: 83-90.

3. Evans JR, Rowe RD, Keith JD (1960) Spontaneous closure of ventricular septal defects. Circulation 1; 22: 1044-1054.

4. Bloomfield DK (1964) The natural history of ventricular septal defects in patients surviving infancy. Circulation 29: 914-955.

5. Hoffman JIE, Rudolph AM (1965) The natural history of ventricular septal defects in infancy. Amer J Cardiol 16: 634-653.

6. Murthy K, Arcilla RA, Moulder PV, Cassels DE (1968) Functional closure of the ventricular septal defect after pulmonary artery banding. J Am Med Assoc 205: 592-594.

7. Edgett JW JR, Nelson WP, Hall RJ, Jahnke EJ, Aaby GV (1968) Spontaneous closure of ventricular septal defects after banding of the pulmonary artery. The American Journal of Cardiology 22: 729-732.

8. Stark J, Tynan M, Aberdeen E (1970) Spontaneous closure of ventricular septal defects following pulmonary artery constriction (banding). Am Heart J 76: 548-551.

9. Rao PS, Linde LM, Liebman J, Perrin E (1974) Functional closure of physiologically advantageous ventricular septal defects: Observations in three cases with tricuspid atresia. Am J Dis Child 127: 36-40.

10. Rao PS (1977) Natural history of the ventricular septal defect in tricuspid atresia and its surgical implications. $\mathrm{Br}$ Heart J 39: 276-288.

11. Rao PS (1982) Natural history of the ventricular septal defect in tricuspid atresia. In: Rao PS, Tricuspid atresia. Chapter 14, Futura Publishing Co, Mount Kisco, 201-229.

12. Rao PS (1983) The ventricular septal defect in tricuspid atresia: Its natural history and surgical importance. King Faisal Spec Hosp Med J 3: 31-42.

13. Rao PS (1983) Further observations on the spontaneous closure of physiologically advantageous ventricular septal defects in tricuspid atresia with special emphasis on the surgical implications. Ann Thorac Surg 35: 121-131.

14. Rao PS (1992) Natural history of the ventricular septal defects in tricuspid atresia. In: Rao PS, Tricuspid Atresia. ( $2^{\text {nd }}$ edn), Futura Publishing Co, Mt. Kisco, 261-293.

15. Rao PS (1983) Physiologically advantageous ventricular septal defects. Pediatr Cardiol 4: 59-62.

16. Rao PS (1992) Spontaneous closure of ventricular septal defects. Pediatr Cardiol 13: 190-191.

17. Rao PS (1991) Subaortic obstruction after pulmonary artery banding in patients with tricuspid atresia and double-inlet left ventricle and ventriculoarterial discordance. J Am Coll Cardiol 18: 1585-1586.

18. Rao PS (1990) Tricuspid atresia. In: Long WA, Fetal and Neonatal Cardiology. WB Saunders, Philadelphia, 525-540.

19. Rao PS (1997) Tricuspid atresia: Anatomy, imaging and natural history. In: Freedom R, Atlas of heart disease: Congenital heart disease. Current Medicine, Philadelphia, 14.0-4.17.

20. Rao PS (2000) Tricuspid atresia. In: Moller JH, Hoffman JIE, Pediatric cardiovascular medicine. New York: Churchill Livingstone, 421-441.

21. Rao PS (2004) Tricuspid atresia. In e-medicine - Pediatrics.

22. Rao PS (2009) Tricuspid atresia. eMedicine from WebMD.

23. Rao PS (2011) Pediatric tricuspid atresia. eMedicine from WebMD.

24. Rao PS (2012) Tricuspid atresia. In: Moller JH, Hoffman JIE, Pediatric cardiovascular medicine. ( $2^{\text {nd }}$ edn), Chapter 35, Wiley-Blackwell/A John Wiley \& Sons Ltd., Oxford, 487508.

25. Rao PS (2013) Tricuspid atresia. In: Vijayalakshmi IB, Rao PS, Chugh R, A comprehensive approach to management of congenital heart diseases. Jaypee Publications, New Delhi, 397-413.

26. (2015) Tricuspid atresia. In: Rao PS, Vidyasagar D, Perinatal cardiology: A multidisciplinary approach. Chapter 22, Cardiotext Publishing, Minneapolis.

27. Rao PS (2015) Tricuspid atresia. In: Gupta P, Menon PSN, Ramji S, Lodha R, PG textbook of pediatrics. Jaypee Brothers Medical Publishers (P) Ltd, New Delhi, 1861-1870.

28. Rao PS (2016) Pediatric tricuspid atresia. Medscape Drugs \& Diseases.

29. Rao PS (2018) Tricuspid atresia. In: Vijayalakshmi IB, Rao PS, Chugh R, A comprehensive approach to management of congenital heart diseases. Jaypee Publications, New Delhi, India.

30. Rao PS (2018) Tricuspid atresia. In: Gupta P, Menon PSN, Ramji S, Lodha R, PG textbook of pediatrics. (2 ${ }^{\text {nd }}$ edn), Jaypee Brothers Medical Publishers (P) Ltd., New Delhi, India.

31. Rao PS (2000) Tricuspid atresia. Curr Treat Options Cardiovasc Med 2: 507-520.

32. Rao PS, Alapati S (2012) Tricuspid atresia in the neonate. Neonatology today $7:$ 1-12.

33. Rao PS (1982) Tricuspid atresia. Futura Publishing Co., 


\section{Mount Kisco.}

34. Rao PS (1992) Tricuspid atresia. (2 ${ }^{\text {nd }}$ edn), Futura Publishing Co., Mount Kisco.

35. Rao PS (1982) Terminology: Tricuspid atresia or univentricular heart. In: Rao PS, Tricuspid atresia. Futura Publishing Co., Mount Kisco, 3-6.

36. Rao PS (1990) Is the term "Tricuspid atresia" appropriate? Am J Cardiol 66: 1251-1254.

37. Rao PS (1992) Terminology: Is tricuspid atresia the correct term to use? In: Rao PS, Tricuspid Atresia. ( $\left.2^{\text {nd }} \mathrm{edn}\right)$, Futura Publishing Co., Mount Kisco, 3-6.

38. Rao PS (1980) A unified classification for tricuspid atresia. Am Heart J 99: 799-804.

39. Rao PS (1982) Classification of tricuspid atresia. In: Rao PS, Tricuspid atresia. Chapter 5, Futura Publishing Co, Mount Kisco, 41-47.

40. Rao PS (1992) Classification of tricuspid atresia. In: Rao PS. Tricuspid atresia. ( $2^{\text {nd }}$ edn), Chapter 5, Futura Publishing Co, Mt. Kisco, NY, 59-79.

41. Rao PS, Jue KL, Isabel-Jones J, Ruttenberg HD (1973) Ebstein's malformation of the tricuspid valve with atresia. Differentiation from isolated tricuspid atresia. Am J Cardiol 32: 1004-1009.

42. Rao PS (1987) Atrioventricular canal mimicking tricuspid atresia: Echocardiographic \& angiographic features. $\mathrm{Br}$ Heart J 58: 409-412.

43. Rao PS, Levy JM, Nikicicz E, Gilbert-Barness EF (1991) Tricuspid atresia: Association with persistent truncus arteriosus. Am Heart J 122: 829-835.

44. Rao PS (1991) Tricuspid atresia with common arterial trunk. Int J Cardiol 30: 367-368.

45. Rao PS (1982) Demographic features of tricuspid atresia. In: Rao PS Tricuspid atresia. Chapter 3, Futura Publishing Co, Mount Kisco, 13-24.

46. Rao PS (1992) Demographic features of tricuspid atresia. In: Rao PS Tricuspid atresia. ( $2^{\text {nd }}$ edn), Chapter 3, Futura Publishing Co., Mt. Kisco, NY, 23-37.

47. Kulangara RJ, Boineau JP, Moore HV, Rao PS (1982) Electrovectorcardiographic features of tricuspid atresia. In: Rao PS, Tricuspid Atresia. Futura Publishing Co., Mount Kisco, 113-126.

48. Kulangara RJ, Boineau JP, Moore HV, Rao PS (1981) Ventricular activation and genesis of QRS in tricuspid atresia. Circulation 64: 6-225.

49. Rao PS, Kulangara RJ, Boineau JP, Moore HV (1992) Electrovectorcardiographic features of tricuspid atresia. In: Rao PS. Tricuspid Atresia. (2 ${ }^{\text {nd }}$ edn), Chapter 9, Futura Publishing Co., Mount Kisco, NY, 141-164.

50. Covitz W, Rao PS (1982) Non-invasive evaluation of patients with tricuspid atresia (Roentgenography, echocardiography, and nuclear angiography). In: Rao PS, Tricuspid Atresia. Chapter 10, Futura Publishing Co., Mount Kisco, 127-145.

51. Covitz W, Rao PS (1992) Non-invasive evaluation of patients with tricuspid atresia (Roentgenography, echocardiography, and nuclear angiography). In: Rao PS, Tricuspid Atresia. (2 ${ }^{\text {nd }}$ edn), Chapter 10, Futura Publishing Co, Mt. Kisco, NY, 165-182.

52. Rao PS (2015) Echocardiographic evaluation of neonates with suspected heart disease. In: Rao PS, Vidyasagar D,
Perinatal Cardiology: A Multidisciplinary Approach. Chapter 11, Cardiotext Publishing, Minneapolis.

53. Rao PS (1983) Left-to-right atrial shunting in tricuspid atresia. Br Heart J 49: 345-349.

54. Rao PS (1982) Cardiac catheterization in tricuspid atresia. In: Rao PS, Tricuspid atresia. Chapter 11, Futura Publishing Co, Mt. Kisco, 153-178.

55. Rao PS (1992) Cardiac catheterization in tricuspid atresia. In: Rao PS. Tricuspid Atresia. ( $\left.2^{\text {nd }} \mathrm{edn}\right)$, Chapter 12, Futura Publishing Co, Mt. Kisco, NY, 193-221.

56. Rao PS, Covitz W, Moore HV (1982) Principles of palliative management of patients with tricuspid atresia. In: Rao PS, Tricuspid atresia. Chapter 15, Futura Publishing Co., Mount Kisco, 233-253.

57. Rao PS, Covitz W, Chopra PS (1992) Principles of palliative management of patients with tricuspid atresia. In: Rao PS, Tricuspid atresia. ( $2^{\text {nd }}$ edn), Chapter 16, Futura Publishing Co, Mt. Kisco, NY, 297-320.

58. Rao PS (2007) Role of interventional cardiology in neonates: Part I. Non-surgical atrial septostomy. Congenital Cardiol Today 5: 1-12.

59. Rao PS (2015) Neonatal catheter interventions. In: Vijayalakshmi IB, Cardiac catheterization and imaging (From Pediatrics to Geriatrics). Jaypee Publications, New Delhi, India, 388-432.

60. Chopra PS, Rao PS (1992) Corrective surgery for tricuspid atresia: Which modifications of Fontan-Kreutzer procedure should be used? A Review. Am Heart J 123: 758-767.

61. Rao PS and Chopra PS (1992) Modification of FontanKreutzer procedures for tricuspid atresia: Can a choice be made? In. Rao PS. Tricuspid Atresia. (2nd edn), Chapter 19, Futura Publishing Co, Mt. Kisco, NY, 361-375.

62. Rao PS (2015) Fontan operation: Indications, short and long term outcomes. Indian J Pediatr 82: 1147-1156.

63. Rao PS (1983) Pathophysiologic consequences of cyanotic congenital heart disease. Indian J Pediatr 50: 479-487.

64. Rao PS (2007) Principles of management of the neonate with congenital heart disease. Neonatology Today 2: 1-10.

65. Rao PS, Vidyasagar D (2015) Perinatal cardiology: A multidisciplinary approach. Cardiotext Publishing, Minneapolis, MN.

66. Rao PS (2009) Diagnosis and management of cyanotic congenital heart disease: Part I. Indian J Pediatr 76: 57-70.

67. Alapati S, Rao PS (2011) Tetralogy of fallot in the neonate. Neonatology Today 6: 1-10.

68. Rao PS (2012) Congenital heart defects - A review. In: Rao PS, Congenital heart disease - Selected aspects. In Tech, Rijeka, Croatia, 3-44.

69. Siblini G, Rao PS, Singh GK, Tinker K, Balfour IC (1997) Transcatheter management of neonates with pulmonary atresia and intact ventricular septum. Cathet Cardiovasc Diagn 42: 395-402.

70. Rao PS (2018) Transcatheter perforation of atretic pulmonary valve in pulmonary atresia with ventricular septal defect. Congenital Cardiology Today 16: 1-8.

71. Rao PS (2008) Role of interventional cardiology in the treatment of neonates: Part III. Congenital Cardiol Today 6: 1-10.

72. Rao PS (2013) Consensus on timing of intervention for 
common congenital heart diseases: Part II - cyanotic heart defects. Indian J Pediatr 80: 663-674.

73. Rao PS (2019) Management of congenital heart disease: State of the art - Part II - Cyanotic heart defects. Children (Basel) 6: 54 .

74. Rao PS, Lawrie GM (1983) Absent pulmonary valve syndrome. Surgical correction with pulmonary arterioplasty. Br Heart J 50: 586-589.

75. Rao PS (2010) Transposition of the great arteries in the neonate. Neonatology Today 5: 1-8.

76. Rao PS (2009) Diagnosis and management of cyanotic congenital heart disease: Part II. Indian J Pediatr 76: 297308.

77. Whitfield CK, Rao PS (2013) Total anomalous pulmonary venous connection in the neonate. Neonatology Today 8: 1-7.

78. Rao PS, Balaguru D (2013) Truncus arteriosus in the neonate. Neonatology Today 8: 1-6.

79. Balaguru D, Rao PS (2013) Truncus arteriosus. In: Vijayalakshmi IB, Rao PS, Chugh R, A comprehensive approach to management of congenital heart diseases. Jaypee Publications, New Delhi, India, 600-613.

80. Alapati S, Rao PS (2011) Hypoplastic left heart syndrome in the neonate. Neonatology Today 6: 1-9.

81. Rao PS (1985) Comprehensive management of pulmonary atresia with intact ventricular septum. Ann Thorac Surg 40: 409-413.

82. Rao PS (2002) Pulmonary atresia with intact ventricular septum. Curr Treat Options Cardiovasc Med 4: 321-336.

83. Buck SH, Rao PS, Kambam J (1994) Double outlet right ventricle. In: Kambam J, Cardiac anesthesia for infants and children. Chapter 28, Mosby-Year Book, St. Louis, MO, 310-319.

84. Rogers JH Jr., Rao PS (1977) Ebstein's anomaly of the left atrioventricular valve with congenital corrected transposition of the great arteries. Diagnosis by intracavitary electrocardiography. Chest 72: 253-256.

85. Rao PS (1990) Other tricuspid valve anomalies. In: Long WA, Fetal and Neonatal Cardiology. WB Saunders, Philadelphia, PA, 541-550.

86. Reddy SC, Chopra PS, Rao PS (1997) Aneurysm of the membranous ventricular septum resulting in pulmonary outflow tract obstruction in congenitally corrected transposition of the great arteries. Am Heart J 133: 112-119.

87. Balaguru D, Rao PS (2015) Ebstein's anomaly of the tricuspid valve in the neonate. Neonatology Today 10: 1-6.

88. Rao PS, Kambam J (1994) Ebstein's malformation of the tricuspid valve. In: Kambam J, Cardiac anesthesia for infants and children. Chapter 29, Mosby-Year Book, St. Louis, MO, 320-332.

89. Balaguru D, Rao PS (2013) Diseases of the tricuspid valve (Ebstein's anomaly, tricuspid stenosis and regurgitation). In: Vijayalakshmi IB, Rao PS, Chugh R, A comprehensive approach to management of congenital heart diseases. Jaypee Publications, New Delhi, India, 414-433.

90. Rao PS, Kulangara RJ, Moore HV, Strong WB (1981) Syndrome of single ventricle without pulmonic stenosis but with left atrioventricular valve atresia and interatrial obstruction. Palliative management with simultaneous atrial septostomy and pulmonary artery banding. J Thorac Cardiovasc Surg 81: 127-130.
91. Balaguru D, Rao PS (2013) Mitral atresia. In: Vijayalakshmi IB, Rao PS, Chugh R, A comprehensive approach to management of congenital heart diseases. Jaypee Publications, New Delhi, India, 458-467.

92. Sharma SK, Rao PS (2008) Interrupted aortic arch. In: The encyclopedic reference of molecular mechanisms of disease. Springer-Verlag, Berlin, Heidelberg, New York, Tokyo.

93. Rao PS, Leonard T (1976) Polysplenia syndrome. Cardiology Digest 11: 14-22.

94. Rao PS (1981) Dextrocardia: Systematic approach to differential diagnosis. Am Heart J 102: 389-403.

95. Rao PS (2015) Cardiac malposition. In: Gupta P, Menon PSN, Ramji S, Lodha R, PG textbook of pediatrics. Jaypee Brothers Medical Publishers (P) Ltd., New Delhi, India, 1807-1816.

96. Rao PS (2018) Cardiac malposition. In: Gupta P, Menon PSN, Ramji S, Lodha R, PG textbook of pediatrics. $\left(2^{\text {nd }}\right.$ edn), Jaypee Brothers Medical Publishers (P) Ltd., New Delhi, India.

97. Rao PS (2013) What an adult cardiologist should know about cyanotic congenital heart disease? J Cardiovasc Dis Diagn 1: 104.

98. Rao PS (2014) What the adult cardiologist should know about cyanotic congenital heart disease. In: Chopra HK, et al. State of Art CSI Cardiology Update 2014.

99. Rao PS, Molthan ME, Lipow HW (1970) Cor pulmonale as a complication of ventriculoatrail shunts. J Neurosurg 33: 221-225.

100. Rao PS (1971) Physiological basis of diuretic drugs. J Indian Med Ass 56: 100-107.

101. Rao PS, Sissman NJ (1971) Congenital heart disease in the de Lange Syndrome. J Pediatr 79: 674-677.

102. Rao PS (1973) Preventive aspects of congenital heart disease. Paediatrician 2: 224-238.

103. Strong WB, Rao PS, Steinbaugh M (1975) Primary prevention of atherosclerosis: A challenge to the physician caring for children. South Med J 68: 319-327.

104. Rao PS (1975) Prevention of pediatric heart disease. Paediatrician 4: 320-342.

105. Rao PS (1977) Preventive aspects of heart disease in infants and children. South Med J 70: 728-740.

106. Rao PS (1977) Prevention of heart disease in infants and children. Curr Probl Pediatr 7: 1-48.

107. Rao PS, Silbert DR (1974) Superior vena caval obstruction in total anomalous pulmonary venous connexion. Br Heart J 36: 228-232.

108. Vincent WR, Rao PS (1973) Early identification of the neonate with suspected serious heart disease. Paediatrician 2: 239-250.

109. Rao PS, Strong WB (1974) Early identification of the neonate with heart disease. J Med Assoc Georgia 63: 430-433.

110. Rao PS (1984) Management of the neonate with suspected serious heart disease. King Faisal Specialist Hospital Med J 4: 209-216.

111. Rao PS (2007) The growing problem of the newborn: An approach to the diagnosis of cyanotic neonate for the primary care provider. Neonatology Today 2: 1-7. 
112. Linde LM, Rao PS (1973) A modern view of infective endocarditis. Cardiovasc Clin 5: 15-34.

113. Thapar MK, Rao PS, Linde LM, Feldman D (1978) Infective endocarditis: A review. I. Incidence, etiology, pathology and clinical features. Paediatrician 7: 65-84.

114. Rao PS, Thapar MK, Linde LM (1978) Infective endocarditis: A review. II. Diagnosis and treatment. Paediatrician 7: 85-99.

115. Rao PS, Marino BL, Robertson AF III (1978) Usefulness of continuous positive airway pressure in the differential diagnosis of cardiac from pulmonary cyanosis in newborn infants. Arch Dis Child 53: 456-460.

116. Rao PS (1981) Present status of surgery in congenital heart disease. Indian J Pediatr 48: 349-361.

117. Chopra PS, Rao PS (1991) Surgical management of congenital heart defects: Current trends. Indian J Pediatr 58: $623-640$.

118. Rao PS (2015) Cardiac malpositions including heterotaxy syndromes. In: Rao PS, Vidyasagar D, Perinatal cardiology: A multidisciplinary approach. Chapter 36, Cardiotext Publishing, Minneapolis, MN.

119. Rao PS (1982) Vasodilator therapy for cardiac failure in pediatric practice. Indian J Pediatr 49: 843-848.

120. Rao PS, Strong WB (1981) Congenital heart disease. In: Current Therapy 1981. Conn HF, WB Saunders, Philadelphia PA, 185-209.

121. Rao PS, Andaya WG (1986) Chronic afterload reduction in infants and children with primary myocardial disease. $J$ Pediatr 108: 530-534.

122. Rao PS (1995) Afterload reduction for dilated cardiomyopathy. Pediatr Cardiol 16: 51.

123. Feteih W, Rao PS, Whisennand $\mathrm{HH}$, Mardini MK, Lawrie GM (1983) Chylopericardium: New complication of Blalock-Taussig anastomosis. J Thorac Cardiovasc Surg 85: 791-798

124. Rao PS (1984) Chylopericardium following BlalockTaussig anastomosis (Letter). J Thorac Cardiovasc Surg 87: 642 .

125. Rao PS, Whisennand HW (1983) Chylopericardium (Letter). Ann Thorac Surg 36: 494-495

126. Mardini MK, Rao PS (1984) Scimitar syndrome: Experience with four patients and review of literature. Arab J Med 3: 13-23.

127. Rao PS, Mardini MK, Feteih W, et al. (1985) Syndrome of absent pulmonary valve. Abstracts of the International Symposium on Cardiovascular Surgery - 1985, Houston, Texas, 141.

128. Rao PS, Mardini MK, Feteih W, et al. (1986) Syndrome of absent pulmonary valve. Abstracts of the $X$ World Congress of Cardiology, Washington, D.C., 475.

129. Rao PS (1987) Mitral valve prolapse syndrome. Indian J Pediatr 54: 140-144.

130. Kambam J, Rao PS (1994) Mitral valve prolapse syndrome (Barlow's syndrome). In: Kambam J, Cardiac anesthesia for infants and children. Chapter 31, Mosby-Year Book, St. Louis, MO, 354-360.

131. Rao PS, Solymar L, Mardini MK, Fawzy ME, Guinn G (1989) Anticoagulant therapy in children with prosthetic valves. Ann Thorac Surg 47: 589-592.
132. Rao PS (1990) Long-term oral diazoxide therapy for pulmonary vascular obstructive disease associated with congenital heart defects. Am Heart J 119: 1317-1321.

133. Rao PS (1991) Perinatal circulatory physiology. Indian J Pediatr 58: 441-451.

134. Rao PS (2008) Perinatal circulatory physiology: Its influence on clinical manifestations of neonatal heart disease - Part I. Neonatology Today 3: 6-12.

135. Rao PS (2008) Perinatal circulatory physiology: Its influence on clinical manifestations of neonatal heart disease - Part II. Neonatology Today 3: 1-10.

136. Rao PS (2009) Perinatal circulatory physiology: Its influence on clinical manifestations of neonatal heart disease - Part I. Congenital Cardiol Today 7: 1-9.

137. Rao PS (2009) Perinatal circulatory physiology: Its influence on clinical manifestations of neonatal heart disease - Part II. Congenital Cardiol Today 7: 1-11.

138. Rao PS (1994) Fetal and neonatal circulation. In: Kambam J, Cardiac anesthesia for infants and children. Chapter 2, Mosby-Year Book, St. Louis, MO., 10-19.

139. Rao PS (2015) Perinatal circulatory physiology. In: Rao PS, Vidyasagar D, Perinatal cardiology: A multidisciplinary approach. Chapter 1, Cardiotext Publishing, Minneapolis, MN.

140. Rao PS (2015) Role of perinatal circulatory physiology on clinical manifestations and management of neonatal heart disease. In: Rao PS, Vidyasagar D, Perinatal cardiology: A multidisciplinary approach. Chapter 2, Cardiotext Publishing, Minneapolis, MN.

141. Solymar L, Rao PS, Mardini MK, Fawzy ME, Guinn G (1991) Prosthetic valves in children and adolescents. Am Heart J 121: 557-568.

142. Rao PS, Solymar L, Fawzy ME, Guinn G (1991) Reassessment of usefulness of porcine heterografts in mitral position in children. Pediatr Cardiol 12: 164-169.

143. Rao PS (1991) Evaluation of cardiac murmurs in children. Indian J Pediatr 58: 471-491.

144. Chopra PS, Reed WH, Wilson AD, Rao PS (1994) Delayed presentation of anomalous circumflex coronary artery arising from pulmonary artery following repair of aortopulmonary window in infancy. Chest 106: 1920-1922.

145. Balfour IC, Rao PS (1998) Chest pain in children. Indian J Pediatr 65: 21-26.

146. Jureidini SB, Marino CJ, Rao PS (1998) Congenital coronary artery abnormalities. Indian J Pediatr 65: 217229.

147. Pugh KJ, Jureidine SB, Ream R, Rao PS, Dossier J (2002) Successful thrombolytic therapy of pulmonary embolism associated with urosepsis in an infant. Pediatr Cardiol 23: 77-79.

148. Gupta-Malhotra M, Rao PS (2005) Current perspectives on Kawasaki disease. Indian J Pediatr 72: 621-629.

149. Rao PS (2008) Cardiac emergencies in pediatric practice. Physician's Digest 17: 30-36.

150. Rao PS (2008) Neonatal cardiac emergencies: Management strategies. Neonatology Today 3: 1-5.

151. Yates MC, Rao PS (2013) Pediatric cardiac emergencies. Emergency Med 3: 164.

152. Rao PS (2015) Neonatal cardiac emergencies: 
Management strategies. In: Rao PS, Vidyasagar D, Perinatal cardiology: A multidisciplinary approach. Chapter 8, Cardiotext Publishing, Minneapolis, MN.

153. Mazur L, de Ybarrondo L, Pickard L, Rao PS (2012) Development of supravalvular pulmonary artery stenosis following a Nuss procedure. J Pediatr Surg 47: e61-e64.

154. Rao PS (2013) Consensus on timing of intervention for common congenital heart diseases: Part I - acyanotic heart defects. Indian J Pediatr 80: 32-38.
155. Banker A, Gupta-Malhotra M, Rao PS (2013) Childhood hypertension: A review. J Hypertens 2: 128.

156. Rao PS (2015) Prevention of sudden death in athletes. Pediat Therapeut 5: e129.

157. Rao PS (2019) Management of congenital heart disease: State of the art; Part I - Acyanotic heart defects. Children (Basel) 6: 42. 